\title{
Membrane Lipids in Plant-Associated Bacteria: Their Biosyntheses and Possible Functions
}

\author{
Isabel M. López-Lara, Christian Sohlenkamp, and Otto Geiger \\ Centro de Investigación sobre Fijación de Nitrógeno, Universidad Nacional Autónoma de México, Apdo. Postal 565-A, \\ Cuernavaca, Morelos, CP62210, México
}

Submitted 3 March 2003. Accepted 6 March 2003.

\begin{abstract}
Membrane lipids in most bacteria generally consist of the glycerophospholipids phosphatidylglycerol, cardiolipin, and phosphatidylethanolamine (PE). A subset of bacteria also possesses the methylated derivatives of PE, monomethylphosphatidylethanolamine, dimethylphosphatidylethanolamine, and phosphatidylcholine (PC). In Sinorhizobium meliloti, which can form a nitrogen-fixing root nodule symbiosis with Medicago spp., PC can be formed by two entirely different biosynthetic pathways, either the PE methylation pathway or the recently discovered PC synthase pathway. In the latter pathway, one of the building blocks for PC formation, choline, is obtained from the eukaryotic host. Under phosphorus-limiting conditions of growth, $S$. meliloti replaces its membrane phospholipids by membrane-forming lipids that do not contain phosphorus; namely, the sulfolipid sulfoquinovosyl diacylglycerol, ornithine-derived lipids, and diacylglyceryl- $N, N, N$-trimethylhomoserine. Although none of these phosphorus-free lipids is essential for growth in culture media rich in phosphorus or for the symbiotic interaction with the legume host, they are expected to have major roles under free-living conditions in environments poor in accessible phosphorus. In contrast, sinorhizobial mutants deficient in PC show severe growth defects and are completely unable to form nodules on their host plants. Even bradyrhizobial mutants with reduced PC biosynthesis can form only root nodules displaying reduced rates of nitrogen fixation. Therefore, in the cases of these microsymbionts, the ability to form sufficient bacterial PC is crucial for a successful interplay with their host plants.
\end{abstract}

Additional keywords: Agrobacterium, Bradyrhizobium, hopanoid, Mesorhizobium, Pseudomonas, Rhizobium.

All living organisms are surrounded by membranes which delimit a cell from external space. Due to their hydrophobic interior, membranes function as diffusion barriers for most hydrophilic substances, raising the possibility for controlled import or export of such substances by the means of specific proteins. In addition to membrane proteins, eubacterial membranes contain so-called bilayer-forming membrane lipids, predominantly consisting of phospholipids but, in some organisms and especially under certain physiological conditions, also of phosphorus-free membrane lipids. In addition to the variation within the head

Corresponding author: O. Geiger; Telephone: +52-777-3131697; Fax: +52-777-3175581; E-mail: otto@cifn.unam.mx. groups, giving origin to the different lipid classes, the fatty acyl chain substitutions within one lipid class vary, and it is clear that the types of fatty acyl residues attached are important for the properties of an individual lipid (Cronan 2002; Sakamoto and Murata 2002). However, there is a lack of studies linking fatty acyl variations within a certain membrane lipid class of plantassociated bacteria with functionality. The outer leaflet of the outer membrane in gram-negative bacteria predominantly is formed by lipopolysaccharides. Their structures, biosyntheses, and functions have been extensively described (Kannenberg et al. 1998; Raetz and Whitfield 2002); therefore, they will not be covered within this review.

As in Escherichia coli, the major phospholipids in plantassociated bacteria are phosphatidylglycerol (PG), cardiolipin (CL), and phosphatidylethanolamine (PE) (Gill 1975; Shukla et al. 1980). Although phosphatidylcholine (PC) or lecithin constitutes the major phospholipid in eukaryotes, neither PC itself, nor any other methylated derivatives of PE, monomethylphosphatidylethanolamine (MMPE), or dimethylphosphatidylethanolamine (DMPE), are encountered in the gram-negative model bacterium $E$. coli or in the gram-positive model bacterium Bacillus subtilis. Therefore, it was thought that MMPE, DMPE, and PC occur only rarely in bacteria (Goldfine 1982). However, the description of PC, MMPE, or DMPE in many genera of diverse eubacterial phylogenetic groups (López-Lara and Geiger 2001; Sohlenkamp et al. 2003) suggests that these lipids are much more widespread in bacteria than previously thought. Phosphatidylserine, another phospholipid found in abundance in eukaryotic membranes, was detected in some rhizobia (Bunn and Elkan 1971; Bunn et al. 1970); however, in most prokaryotes, it seems to be present only in minor amounts in its function as a biosynthetic intermediate for PE biosynthesis (Miller et al. 1990). Phosphatidylinositol (PI) and its phosphorylated derivatives play a central role in eukaryotic signaling. Likewise, PI plays an important role in some bacteria. For example, in Mycobacterium spp., PI is a major and essential membrane component (Jackson et al. 2000). PI has been reported to be formed under low oxygen concentrations in Bradyrhizobium japonicum (Tang and Hollingsworth 1998); however, in this latter case, its potential role for the interaction with plant hosts has not been studied.

During the course of this review, the focus will be on biosyntheses of membrane lipid classes and their possible functions, mainly using the example of Sinorhizobium meliloti.

Phospholipid biosynthesis in plant-associated bacteria.

Based mainly on studies in E. coli and Bacillus subtilis, it is generally thought that most bacteria would follow the biosyn- 
thesis schemes and enzyme activities discovered in these two model bacteria (Heath et al. 2002). Our model for phospholipid biosynthesis in Sinorhizobium (Rhizobium) meliloti, proposed here (Fig. 1), is largely based on that assumption and whether homologues of the functional gene products can be detected in the $S$. meliloti genome (Fig. 1, table).

Usually, glycerol-3-phosphate acyltransferase (PlsB) catalyzes the first acylation of position 1 of $s n$-glycerol-3-phosphate. However, a PlsB homologue cannot be found in the genome sequence of S. meliloti (Fig. 1) and, at this point, it is unclear which sinorhizobial gene encodes for such an enzyme activity. The second fatty acid is added by another enzyme, 1-acyl-glycerol3-phosphate acyltransferase (PlsC), to form phosphatidic acid (PA). The conversion of phosphatidic acid to CDP-diacylglycerol (CDP-diglyceride) is catalyzed by CDP-diacylglycerol synthetase (CdsA) (Fig. 1). CDP-diacylglycerol can be regarded as the central activated intermediate in bacteria from which individual phospholipid biosynthesis pathways branch off.

Phosphatidylglycerol phosphate synthase (PgsA) transfers $s n$-glycerol-3-phosphate to CDP-diacylglycerol under the release of CMP, thereby producing phosphatidylglycerol phosphate (PGP) (Fig. 1). At least two enzymes with PGP phosphatase activity (PgpA and $\mathrm{PgpB}$ ) in E. coli release inorganic phosphate from PGP to form PG. In the sinorhizobial genome sequence, neither a PgpA nor PgpB homologue can be detected and it is presently unclear which sinorhizobial gene codes for PGP phosphatase activity. CL synthase (Cls) condenses two PG molecules to yield CL and free glycerol in a transesterification reaction (Fig. 1).

Interestingly, some derivatives of $\mathrm{PG}$, the $O$-aminoacyl phosphatidylglycerols, can become major phospholipids in some bacteria. In these lipids, an amino acid is esterified to the $s n-3$ position of the head group glycerol of PG. The most common amino acid in $O$-aminoacyl phosphatidylglycerols is lysine, but the occurrence of ornithine and alanine has been reported as well (Goldfine 1982). Such modifications can eliminate the net negative charge of PG, thereby increasing the resistance against antimicrobial cationic peptides of the innate immune response. The $m p r F$ gene, required for the lysine modification of PG, recently has been identified in Staphylococcus aureus (Peschel et al. 2001). A very good homologue of $\mathrm{MprF}$ is present in the Sinorhizobium meliloti 1021 genome (Fig. 1, table) and has been reported earlier from the acidtolerant S. meliloti WR101 as the "low pH inducible" LpiA locus (Glenn et al. 1999) as well as recently from the highly acid-tolerant bean microsymbiont Rhizobium tropici CIAT899 (Vinuesa et al. 2003). Therefore, the question arises whether, in $S$. meliloti and in other rhizobia, a lysine modification of PG is occurring under certain conditions (i.e., under acidic conditions of growth or when rhizobia get in contact with their host plants).

The first step in the synthesis of PE is the condensation of CDP-diacylglycerol with serine to form phosphatidylserine (PS) catalyzed by PS synthase (Pss) (Fig. 1). The second step in the formation of PE is the decarboxylation of PS, catalyzed by PS decarboxylase (Psd).

\section{Bacterial phosphatidylcholine biosynthesis.}

$\mathrm{PC}$ or lecithin is the major membrane-forming phospholipid in eukaryotes and is essential for their survival. Eukaryotic organisms usually possess two alternative pathways for PC biosynthesis, the CDP-choline pathway and the methylation pathway (Kent 1995). In the CDP-choline pathway, choline is activated to choline phosphate and subsequently to CDP-choline, which condenses with diacylglycerol to obtain PC. In the methylation pathway, PE is $N$-methylated three times by phospholipid $N$ methyltransferase (Pmt) using $S$-adenosylmethionine (SAM) as the methyl donor in order to yield PC via the intermediates MMPE and DMPE.

In bacteria, PC was thought to occur in only a few species and it was speculated that, in such highly specialized bacteria, PC might fulfill a special function. In the case of members of the Rhizobiaceae, which are able to form nitrogen-fixing root nodules on legume host plants, the idea was propagated that rhizobial PC might be of importance for a successful interaction with the eukaryotic host (Geiger 1998; Goldfine 1982; Miller et al. 1990). Although many prokaryotes lack PC, it can be found in significant amounts in membranes of rather diverse bacteria and, based on the bacterial genomes sequenced up to date, it is estimated that more than $10 \%$ of all bacteria possess PC (Sohlenkamp et al. 2003).

Initial studies on PC biosynthesis in prokaryotes were carried out with the tumor-inducing plant pathogen Agrobacterium tumefaciens by Law and associates (Kaneshiro and Law 1964; Sherr and Law 1965). They demonstrated a methyltransferase activity in cell-free extracts of A. tumefaciens which could carry out all three methylations to convert PE to PC using the methyl donor SAM. They also observed a fast, apparently direct incorporation of choline into phospholipids which they could not explain at the time. Enzymatic activities of the CDPcholine pathway were not detected in A. tumefaciens; therefore, it was believed for many years that bacteria possess only the $N$-methylation pathway for PC biosynthesis. The first bacterial gene for a Pmt ( $p m t A)$ was isolated from Rhodobacter sphaeroides (Arondel et al. 1993) and it encodes for a soluble $23-\mathrm{kDa}$ protein that is able to $N$-methylate PE three times in order to obtain PC. The Rhodobacter PmtA does not show significant similarity to any of the methyltransferases from yeast or mammals. Also, the gene ( $p m t A)$ for Pmt activity from $S$. meliloti has been isolated (de Rudder et al. 2000) and, although, it encodes a soluble protein of $22 \mathrm{kDa}$ as well which, upon its expression in E. coli converts PE to PC, the sinorhizobial PmtA shows little similarity to the corresponding Rhodobacter sphaeroides enzyme; therefore, it has been proposed to belong to a new family of Pmt enzymes (de Rudder et al. 2000; López-Lara and Geiger 2001; Sohlenkamp et al. 2003). The similarities between the Rhodobacter PmtA, the Sinorhizobium PmtA, and other SAM-dependent methyltransferases from prokaryotes or eukaryotes are restricted to a small stretch of sequence around the motif VLE/DXGXGXG, described as being characteristic for methyltransferases (Haydock et al. 1991) and thought to be involved in the binding of the methyl donor SAM (Ingrosso et al. 1989). The Sinorhizobium Pmt type shows homology to rRNA methylases, whereas the Rhodobacter Pmt type shows homology to UbiE (ubiquinone/menaquinone biosynthesis methyltransferase) (López-Lara and Geiger 2001; Sohlenkamp et al. 2003).

Recently, two more genes encoding phosphatidylethanolamine $N$-methyltransferases have been cloned from Acetobacter aceti (Hanada et al. 2001) and Bradyrhizobium japonicum (Minder et al. 2001). The PmtA from B. japonicum belongs to the sinorhizobial Pmt family whereas the PmtA from Acetobacter aceti belongs to the Rhodobacter family (Table 1) of Pmts. Searches in data banks for further open reading frames (ORFs) belonging to the two different Pmt families, the rhodobacterial or the sinorhizobial, identified numerous candidates (Table 1). Some of these predicted gene products are from organisms that have been reported to contain PC or its methylated precursors MMPE and DMPE. ORFs encoding for homologues of the S. meliloti PmtA (de Rudder et al. 2000) were found in the genomes of Agrobacterium tumefaciens, Rhizobium leguminosarum bv. viciae, Brucella melitensis, Mesorhizobium loti, Rhodopseudomonas palustris, Acidithiobacillus (formerly Thiobacillus) ferrooxidans, Thermobifida fusca, Burkholderia pseudomallei, 


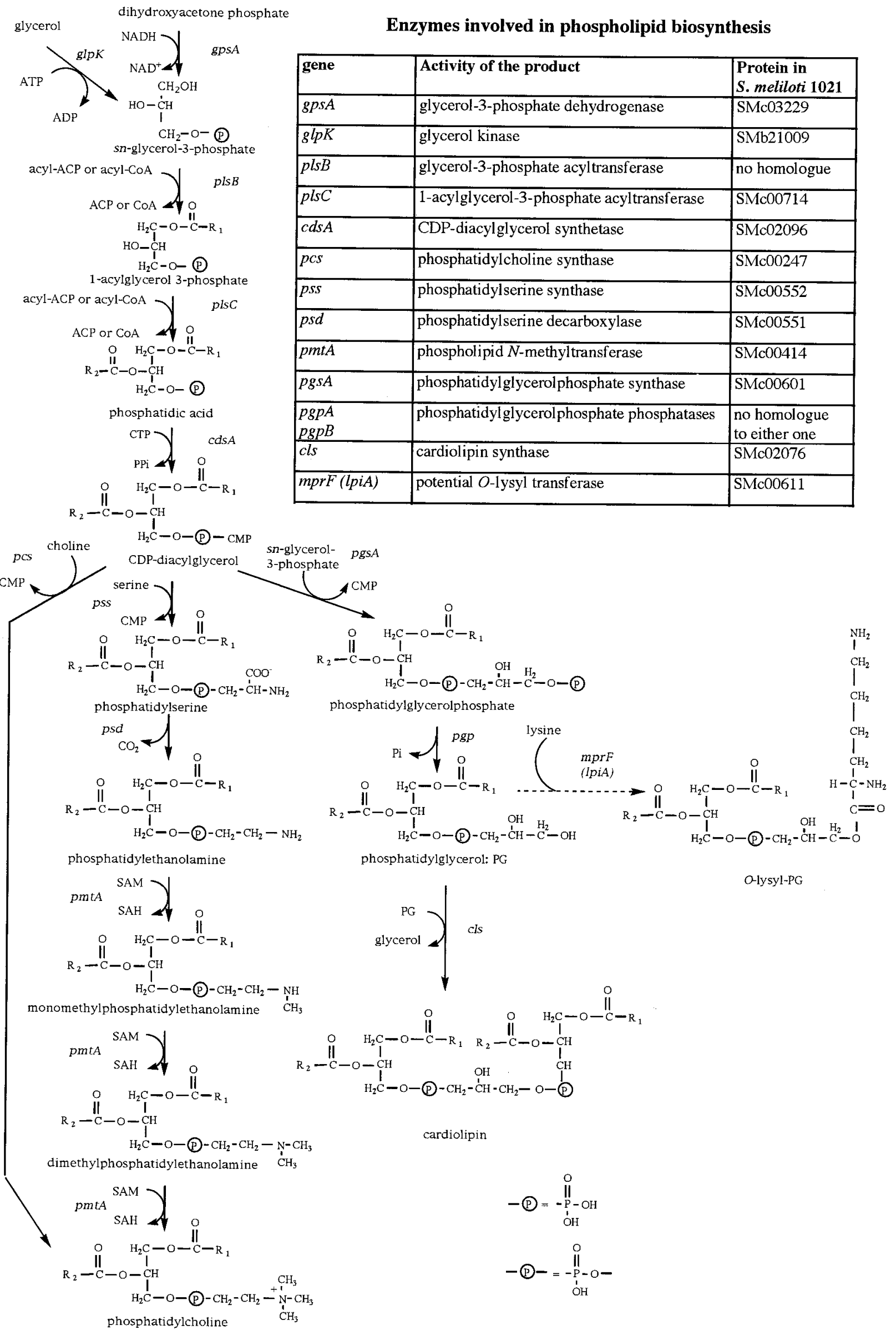

Fig. 1. Model for phospholipid biosynthesis in Sinorhizobium (Rhizobium) meliloti. 
B. mallei, and Bacillus anthracis (Table 1). Homology to Rhodobacter sphaeroides PmtA (Arondel et al. 1993) was found in ORFs deduced from the genomes of Rhizobium leguminosarum, Rhodopseudomonas palustris, Legionella pneumophila, Methylococcus capsulatus, Pseudomonas aeruginosa, Acidithiobacillus ferrooxidans, Pyrococcus furiosus, and Methanosarcina barkeri (Table 1). Although, at this point, it seems impossible to predict which of the homologous ORFs encode for functional Pmts, it is clear, for some of them, that they might not do so. For example, neither the potential Pmt-encoding ORF from Pseudomonas aeruginosa (Wilderman et al. 2002) nor the PmtA-homologous ORFs detected in the genomes of the archaea Pyrococcus furiosus and $M$. barkeri seem to encode for functional Pmts (Sohlenkamp et al. 2003).

In some bacteria, based on genomic predictions, two or even three methyltransferases with specificities for the different methylation steps might be present. The PmtA from Bradyrhizobium japonicum formed predominantly MMPE from PE upon expression in E. coli (Minder et al. 2001). In contrast, when the pmtA genes from $S$. meliloti or Rhodobacter sphaeroides were expressed in E. coli, the main product was PC (Arondel et al. 1993; de Rudder et al. 2000). This result indicates that the bradyrhizobial PmtA might have a specificity for PE and does not work efficiently with MMPE or DMPE as substrates (Minder et al. 2001). Surprisingly, B. japonicum mutants deficient in PmtA still produced low levels of PC, although the amount of PC formed in such mutants $(6 \%$ of total phospholipids) was greatly decreased compared with the wild type (52\% of total phospholipids) after growth in free-living conditions. These results suggest the presence of a second phospholipid $N$-methyltransferase (PmtX) (Minder et al. 2001) which predominantly would perform the methylation of MMPE and DMPE to form PC. Therefore, the so-far hypothetic PmtX might resemble the class I phospholipid $N$-methyltransferases from yeasts and fungi with regard to substrate specificity. Based on the genome sequence of $B$. japonicum, at least two ORFs homologous to the rhodobacterial PmtA (Table 1) constitute good candidates for PmtX. Phospholipid methylation with several enzymes involved also might occur in Rhizobium leguminosarum and in the PC-containing bacterium Rhodopseudomonas palustris (Table 1).

\section{Phosphatidylcholine synthase pathway is unique to some bacteria.}

In PC-containing prokaryotes, only the methylation pathway of PC biosynthesis was thought to occur (Rock et al. 1996). S. meliloti mutants defective in Pmt activity do not form any methylated derivatives of PE, MMPE, DMPE, or PC in their membranes when grown in choline-free medium (de Rudder et al. 1999). Surprisingly, if these Pmt-deficient sinorhizobial mutants are grown in complex medium or a choline-containing minimal medium, PC is formed in wild-type amounts. However, the methylated intermediates (MMPE or DMPE) of a potential Pmt pathway are not formed in such mutants (de Rudder et al. 1997, 1999). These results suggested the existence of a second, methylation-independent pathway for PC

Table 1. Bacteria containing open reading frames (ORFs) probably involved in phosphatidylcholine (PC) biosynthesis ${ }^{\mathrm{a}}$

\begin{tabular}{|c|c|c|c|c|}
\hline \multirow[b]{2}{*}{ Organism $^{\text {b }}$} & \multicolumn{3}{|c|}{ Query (number of amino acids) } & \multirow[b]{2}{*}{ PC } \\
\hline & $\begin{array}{c}\text { Pcs (241) } \\
\text { Sinorhizobium meliloti }\end{array}$ & $\begin{array}{l}\text { PmtA (200) } \\
\text { S. meliloti }\end{array}$ & $\begin{array}{c}\text { PmtA (203) } \\
\text { Rhodobacter sphaeroides }\end{array}$ & \\
\hline \multicolumn{5}{|l|}{$\begin{array}{l}\text { Proteobacteria } \\
\alpha-\text { Subdivision }\end{array}$} \\
\hline Acetobacter aceti $i^{\mathrm{n}}$ & $\ldots$ & $\ldots$ & $* 1 \times 10^{-38}$ & + \\
\hline Agrobacterium tumefaciens $^{\mathrm{c}}$ & $10^{-114}$ & $5 \times 10^{-74}$ & & + \\
\hline Bradyrhizobium japonicum ${ }^{\mathrm{c}}$ & $2 \times 10^{-49}$ & $* 1 \times 10^{-30}, 7 \times 10^{-19}, 2 \times 10^{-17}$ & $9 \times 10^{-37}, 7 \times 10^{-35}$ & + \\
\hline Brucella melitensis & $7 \times 10^{-85}$ & $9 \times 10^{-67}$ & & + \\
\hline Mesorhizobium loti MAFF303099c & $2 \times 10^{-79}$ & $7 \times 10^{-64}, 2 \times 10^{-13}$ & & $\ldots$ \\
\hline Rhizobium leguminosarum ${ }^{\mathrm{u}}$ & $10^{-117}$ & $1 \times 10^{-76}, 1 \times 10^{-19}$ & $4 \times 10^{-33}$ & + \\
\hline Rhodobacter sphaeroides ${ }^{\mathrm{u}}$ & $1 \times 10^{-45}$ & $\ldots$ & $* 10^{-110}$ & + \\
\hline Rhodopseudomonas palustris ${ }^{\mathrm{u}}$ & $2 \times 10^{-47}$ & $2 \times 10^{-28}$ & $1 \times 10^{-37}, 6 \times 10^{-34}$ & $\ldots$ \\
\hline Sinorhizobium meliloti $^{\mathrm{c}}$ & $* 10^{-135}$ & $* 10^{-111}$ & $\ldots$ & + \\
\hline \multicolumn{5}{|l|}{$\beta$-Subdivision } \\
\hline Burkholderia mallei ${ }^{\mathrm{u}}$ & $\ldots$ & $2 \times 10^{-16}$ & $\ldots$ & $\ldots$ \\
\hline Burkholderia pseudomallei ${ }^{\mathrm{u}}$ & $\ldots$ & $2 \times 10^{-16}$ & $\cdots$ & $\cdots$ \\
\hline \multicolumn{5}{|l|}{$\gamma$-Subdivision } \\
\hline Acidithiobacillus ferrooxidans $\mathrm{s}^{\mathrm{u}}$ & $\ldots$ & $5 \times 10^{-18}$ & $1 \times 10^{-18}$ & + \\
\hline Escherichia colic $\mathrm{c}^{\mathrm{J}}$ & $\ldots$ & $\ldots$ & $\ldots$ & - \\
\hline Legionella pneumophila ${ }^{\mathrm{u}}$ & $2 \times 10^{-28}$ & $\ldots$ & $7 \times 10^{-31}$ & $\ldots$ \\
\hline Methylococcus capsulatus ${ }^{\mathrm{u}}$ & $\ldots$ & $\ldots$ & $6 \times 10^{-43}, 3 \times 10^{-15}$ & $\ldots$ \\
\hline Pseudomonas aeruginosa ${ }^{\mathrm{c}}$ & $* 9 \times 10^{-37}$ & $\ldots$ & $4 \times 10^{-11}$ & + \\
\hline Pseudomonas fluorescens ${ }^{\mathrm{u}}$ & $8 \times 10^{-36}$ & $\ldots$ & $\ldots$ & $\ldots$ \\
\hline Pseudomonas syringae & $8 \times 10^{-35}$ & $\ldots$ & $\ldots$ & $\ldots$ \\
\hline Xanthomonas campestris ${ }^{\mathrm{c}}$ & $\ldots$ & $2 \times 10^{-12}$ & $\ldots$ & $\ldots$ \\
\hline \multicolumn{5}{|l|}{ Firmicutes } \\
\hline Bacillus anthracis ${ }^{\mathrm{u}}$ & $\ldots$ & $2 \times 10^{-12}$ & $\ldots$ & $\ldots$ \\
\hline Bacillus subtilis ${ }^{\mathrm{c}}$ & $\ldots$ & $\ldots$ & $\ldots$ & - \\
\hline Desulfitobacterium hafniense ${ }^{\mathrm{u}}$ & $\ldots$ & $6 \times 10^{-19}$ & $\ldots$ & $\ldots$ \\
\hline Thermobifida fusca ${ }^{\mathrm{u}}$ & $\ldots$ & $\ldots$ & $1 \times 10^{-14}$ & $\ldots$ \\
\hline \multicolumn{5}{|l|}{ Spirochetes } \\
\hline Borrelia burgdorferi ${ }^{\mathrm{c}}$ & $2 \times 10^{-27}$ & $\ldots$ & $\ldots$ & + \\
\hline \multicolumn{5}{|l|}{ Archaea } \\
\hline Methanosarcina barkeri ${ }^{\mathrm{u}}$ & $\ldots$ & $\ldots$ & $1 \times 10^{-15}, 8 \times 10^{-11}$ & - \\
\hline Pyrococcus furiosus ${ }^{\mathrm{c}}$ & $\ldots$ & $\ldots$ & $4 \times 10^{-18}$ & - \\
\hline
\end{tabular}

\footnotetext{
${ }^{a}$ Expect (E) values obtained for the deduced ORFs using the indicated queries. E values were obtained using the BLOSUM62 matrix and the program TBLASTN 2.2.5.

${ }^{\mathrm{b}}$ Superscript $\mathrm{c}=$ completed genome sequence, $\mathrm{u}=$ unfinished genome sequence, and $\mathrm{n}=$ not from a genome project. An asterisk $(*)$ precedes numbers
} when the respective enzymatic activity has been demonstrated. 
biosynthesis in $S$. meliloti. In minimal medium, the synthesis of PC via the novel pathway was dependent on the addition of choline (de Rudder et al. 1999). As described for the close relative Agrobacterium tumefaciens (Sherr and Law 1965), the intermediates of the CDP-choline pathway for PC biosynthesis were not detected in $S$. meliloti, although a rapid incorporation of radiolabeled choline into PC was observed in both cases (de Rudder et al. 1999; Sherr and Law 1965). The second pathway for PC biosynthesis in $S$. meliloti involves a novel enzymatic activity, phosphatidylcholine synthase (Pcs), that condenses choline directly with CDP-diacylglycerol to form PC in one step and CMP as the second product (de Rudder et al. 1999) (Fig. 1).

The gene ( $p c s$ ) coding for Pcs activity from $S$. meliloti has been isolated (Sohlenkamp et al. 2000) and is predicted to encode a highly hydrophobic protein of 241 amino acids. Secondary structure predictions propose six, seven, or eight transmembrane helices for the encoded protein depending on the program used. Data base searches revealed significant similarities to other CDP-alcohol phosphatidyltransferases. Relatively high similarity was found to some Pss (i.e., E value $9 \times 10^{-6}$ for Pss from Helicobacter pylori if compared with Pcs from $S$. meliloti), enzymes catalyzing the condensation of serine with CDP-diacylglycerol to yield phosphatidylserine and CMP (Fig. 1). However, more similar potential CDP-alcohol phosphatidyltransferases can be detected in a number of genomes from plant-associated bacteria (Table 1).

Good Pcs homologues can be found in the genomes of many other $\alpha$-proteobacteria, such as A. tumefaciens, Rhizobium leguminosarum bv. viciae, Brucella melitensis, M. loti, Bradyrhizobium japonicum, Rhodopseudomonas palustris, and Rhodobacter sphaeroides (Table 1). However, there are ORFs with good similarity to $S$. meliloti Pcs found in representatives of distantly related bacterial groups such as in the Pseudomonas spp. $P$. aeruginosa, $P$. fluorescens, and $P$. syringae, as well as in Legionella pneumophila and Borrelia burgdorferi (Table 1).

A very good Pcs homologue is present in the genome of the plant pathogen $A$. tumefaciens ( $80 \%$ amino acid identity). $\mathrm{Re}$ cently, a phosphatidylserine synthase (pss)-deficient mutant of A. tumefaciens has been described (Karnezis et al. 2002) which, surprisingly, was only slightly impaired in growth. As expected, this pss-deficient mutant of A. tumefaciens does not form any PE, but does form PC. The substrate (PE) for a potential Pmt pathway is missing in this pss-deficient mutant; therefore, it is impossible that the PC encountered in this organism is formed via a methylation pathway. These results suggest that there exists a functional Pcs pathway for PC biosynthesis in A. tumefaciens. In Agrobacterium spp., the expression of Pss and, therefore, presumably, the formation of PE seems to be required for the formation of the extracellular polysaccharide curdlan (Karnezis et al. 2002).

$P$. aeruginosa synthesizes PC as a minor membrane phospholipid when grown on a complex medium (Goldfine 1982). Recently, the gene coding for the Pcs homologue in $P$. aeruginosa has been inactivated and such a mutant is unable to synthesize PC. Expression of the pseudomonal pcs homologue in $E$. coli causes incorporation of radiolabeled choline into PC in this strain, strongly suggesting that the pseudomonal pcs homologue codes indeed for a Pcs activity (Wilderman et al. 2002). Based on these results, the Pcs pathway might be the only pathway for PC biosynthesis in $P$. aeruginosa and a similar situation might exist in other pseudomonads (Table 1).

No ORFs homologous to the S. meliloti pcs gene can be found in any of the eukaryotic genomes that have been sequenced to date or in the expressed sequence tags derived from all classes of eukaryotes that can be accessed in public databases (Sohlenkamp et al. 2003). This strongly suggests that pcs genes of the $S$. meliloti type and the Pcs pathway encoded are typically prokaryotic and do not exist in eukaryotes.

The majority of bacteria possessing Pcs homologues live in close association with eukaryotic organisms. Therefore, it has been speculated that Pcs might play an important role during pathogen- or symbiont-host interaction (de Rudder et al. 1999, 2000; López-Lara and Geiger 2001; Sohlenkamp et al. 2003). In the case of $S$. meliloti, the choline required for synthesizing PC via the Pcs pathway may be supplied by its legume host plants (de Rudder et al. 1999). Roots of different host plants (Medicago sativa, Melilotus alba, and Medicago officinalis) of $S$. meliloti exude choline in sufficient amounts to allow for maximal PC biosynthesis in S. meliloti via the Pcs pathway and, thereby, the energy-consuming methylation pathway requiring three SAMs for each PC formed (Fig. 1) can be circumvented (de Rudder et al. 1999). Animal or human hosts also contain considerable amounts of choline in their body fluids (Sheard et al. 1986) and it is interesting to note that, besides plant-symbiotic (S. meliloti, Rhizobium leguminosarum, Mesorhizobium loti, Bradyrhizobium japonicum) and saprophytic bacteria (Rhodopseudomonas palustris, Rhodobacter sphaeroides, $P$. fluorescens), animal pathogens such as $P$. aeruginosa, Borrelia burgdorferi, Legionella pneumophila, and Brucella melitensis, as well as plant pathogens such as $A$. tumefaciens and $P$. syringae, also possess genes probably coding for a Pcs activity and probably enabling them to obtain choline for PC biosynthesis directly from their animal, human, or plant hosts. Furthermore, phospholipase C or D or sphingomyelase activities of pathogens destroy host membranes but, at the same time, release choline phosphate or choline, respectively (Chan et al. 2000; Lisa et al. 1994; Wilderman et al. 2001). Choline phosphate can be converted to choline by phosphatases, and the increased amounts of choline provided also could be used by Pcs to synthesize PC.

\section{Distribution}

of phosphatidylcholine biosynthesis pathways in bacteria.

In $S$. meliloti, two pathways for the biosynthesis of PC exist (Fig. 1). Based on the homology of different ORFs deduced from bacterial genomes, we have proposed Pmt or Pcs activities in earlier sections. In the case of Rhizobium leguminosarum, M. loti, Rhodobacter sphaeroides, Rhodopseudomonas palustris, A. tumefaciens, Brucella melitensis, and Legionella pneumophila, in addition to Pcs homologues, good homologues to PmtAs have been identified (Table 1) and we think that, in these organisms, a situation might exist similar to that in $S$. meliloti, and that these bacteria might possess the Pcs as well as the Pmt pathway for PC biosynthesis. Although a rhodobacterial PmtA homologue had been identified in P. aeruginosa (López-Lara and Geiger 2001), it seems not to encode a functional Pmt (Wilderman et al. 2002); therefore, the Pcs pathway seems to be the only pathway for PC biosynthesis in P. aeruginosa. No good Pmt homologues were detected in the genome sequences of $P$. syringae or of $P$. fluorescens; therefore, we also propose that these two pseudomonads possess only the Pcs pathway for PC biosynthesis.

A potential application comes from the observation that strains of $S$. meliloti deficient in the methylation pathway are dependent on the supply of choline for PC biosynthesis and normal growth (de Rudder et al. 2000). Therefore, such strains should be able to thrive in association with a choline provider like a plant but should be eliminated quickly from soil due to their much-reduced growth when they are in free-living conditions and not in the neighborhood of a choline source. Making use of this characteristic, it should be possible to restrict a Pmtdeficient strain to the plant rhizosphere and avoid the unwanted spread of such strains in field inoculation practices. Such addi- 
tional limiting traits might be desirable in bacteria that have been engineered for competitiveness and persistence in the rhizosphere (Savka et al. 2002).

\section{Functional roles of phosphatidylcholine and other membrane phospholipids.}

The functional roles of the major phospholipids in E. coli, PG, $\mathrm{CL}$, and PE, have been studied to some extent (Dowhan and Bogdanov 2002). There are specific roles for each of these individual $E$. coli phospholipids in the association with specific intrinsic membrane proteins, in the organization of protein complexes, in providing binding sites for peripheral membrane proteins, in the translocation of proteins across membranes, in the lipochaperone-assisted folding of membrane proteins, and in lipid domain formation (Dowhan and Bogdanov 2002). Some phospholipids (PE and PI) of plant-pathogenic bacteria constitute important components for the functionality of the ice nucleation protein involved in plant frost injury (Palaiomylitou et al. 1998).

The appearance of PC in rhizobia as a major membrane compound prompted several authors (Geiger 1998; Goldfine 1982; Miller et al. 1990) to suggest that it might play an important role during plant infection. Accordingly, PC should be detectable in bacteroids, the symbiotic state of rhizobia within nodules. Although PC was found to represent the major phospholipid in bacteroids of a Bradyrhizobium subsp. infecting Lotus pedunculatus (Gerson and Patel 1975), a recent study with free-living $B$. japonicum showed that the amount of this phospholipid was greatly reduced in cells grown under lowoxygen conditions compared with aerobically grown cells (Tang and Hollingsworth 1998). These microaerobic conditions are comparable to those in the symbiotic state; therefore, the small amount of PC seemed to question its significance in symbiosis. B. japonicum mutants deficient in the pmtA geneencoded Pmt had much less PC in their membranes than the corresponding wild type (Minder et al. 2001). When soybean host plants of B. japonicum were inoculated with these mutants, only inefficient nodules were formed. The analysis of these nodules revealed a greatly reduced number of normally shaped bacteroids within the plant cells accompanied by an increased amount of starch granules and lower amounts of leghemoglobin. Accordingly, the specific symbiotic nitrogen fixation activity of nodules infected with the pmtA-deficient mutant was decreased to only $18 \%$ of that of the wild type. Further plant infection tests showed that the $B$. japonicum pmtA was able to complement this nitrogen fixation phenotype. When the ex planta growth phenotype of a PmtA-deficient mutant of $B$. japonicum was analyzed, a slightly elevated generation time was observed in cells growing under aerobic conditions. This growth defect was more severe when the cells were grown under microaerobic conditions (Minder et al. 2001). The defective symbiotic phenotype of the pmtA-deficient mutants (Minder et al. 2001) proves that normal bradyrhizobial PC biosynthesis is strictly required for the establishment of a productive host-microbe relationship. The symbiotic defect probably is related to the greatly reduced number of bacteroids in root nodule cells infected with the pmtA-deficient $B$. japonicum strain. On the basis of these results, it can be proposed that the $p m t A$ gene product is necessary for a functional symbiosis between $B$. japonicum and soybean, presumably by providing the major membrane component PC in sufficient quantities (Minder et al. 2001).

Recent results from our laboratory demonstrate that $S$. meliloti mutants, deficient in the pcs and the pmtA pathway and, therefore, completely lacking PC (de Rudder et al. 2000), are unable to form any root nodules on their legume host, alfalfa (Sohlenkamp et al. 2003). In S. meliloti, PC is required for normal growth (de Rudder et al. 2000). On choline-free minimal medium, Pmt-deficient mutants lack PC formation and grow significantly slower than the corresponding wild type (generation times approximately 13 and $7.5 \mathrm{~h}$, respectively). This Pmt-deficient growth phenotype can be rescued either by re-introducing the sinorhizobial pmtA gene or by adding choline to the minimal medium and, thereby, allowing PC biosynthesis via the Pcs pathway in Pmt-deficient mutants. Double knockout mutants deficient in Pmt and Pcs are unable to form PC and show reduced growth even in the presence of choline (de Rudder et al. 2000).

PC is an important membrane lipid in several plant-pathogenic bacteria such as $A$. tumefaciens, $P$. aeruginosa, or $P$. syringae; therefore, it will be interesting to investigate if mutants of these bacteria deficient in PC biosynthesis will be impeded in their pathogenicity.

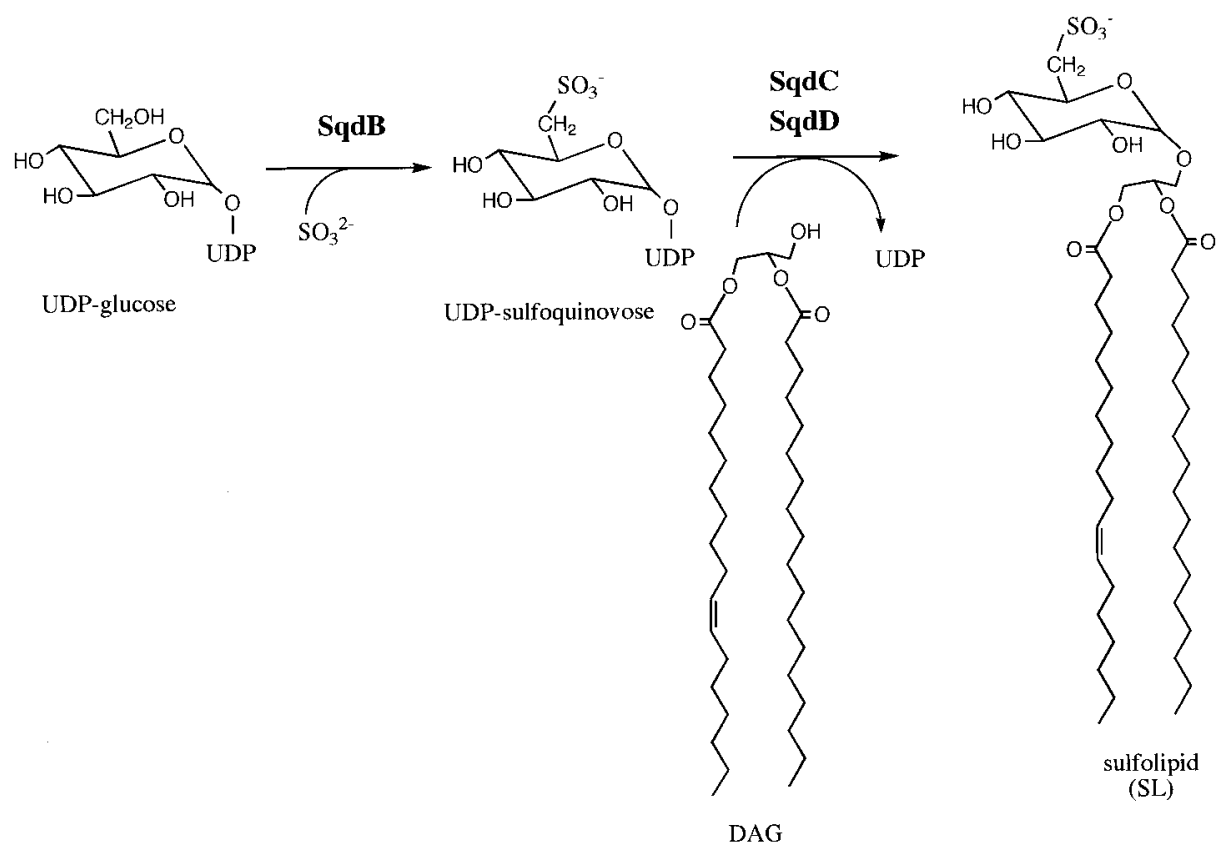

Fig. 2. Model for the biosynthesis of the sulfolipid sulfoquinovosyl diacylglycerol (SL). DAG = diacylglycerol. 
The reason why a PC deficiency has such drastic effects in $S$. meliloti, where growth is strongly reduced when $\mathrm{PC}$ is lacking, and why a deficiency of PC in Zymomonas mobilis (Tahara et al. 1994) or Rhodobacter sphaeroides (Arondel et al. 1993) cannot be correlated with any phenotype presently is not clear.

\section{Phosphorus-free membrane lipids.}

Limitations of nitrogen and phosphate are physiological stress situations frequently encountered by organisms living in natural environments. Some free-living soil bacteria have developed mechanisms in order to use less phosphorus for the biosynthesis of their cell constituents. Under phosphate-limiting conditions of growth, the cell wall composition of Bacillus subtilis changes drastically and phosphorus-containing teichoic acid is quantitatively replaced by phosphorus-free teichuronic acid (Merad et al. 1989). Also, under phosphate stress, membrane phospholipids are at least partially replaced by lipids containing no phosphorus, as demonstrated in $B$. subtilis (Minnikin et al. 1972), $P$. diminuta (Minnikin et al. 1974), $P$. fluorescens (Minnikin and Abdolrahimzadeh 1974), and Rhodobacter sphaeroides (Benning et al. 1995). In S. meliloti, these phosphorus-free lipids are sulfoquinovosyl diacylglycerol (SL), ornithine-derived lipids (OL), and diacylglyceryl- $N, N, N$ trimethylhomoserine (DGTS) and, in S. meliloti, the regulator gene $p h o B$ mediates phosphate stress-controlled synthesis of the membrane lipid DGTS (Geiger et al. 1999).

\section{Glycolipids.}

Glycosyl diacylglycerols are widespread membrane glycolipids in plants, animals, and gram-positive bacteria but rarely are found in gram-negative bacteria. However, in the $\alpha$-proteobacterium Rhodobacter sphaeroides, under phosphate-limited growth conditions, a diglycosyl diacylglyceride, containing glucose and galactose in its head group, is formed (Benning et al. 1995). Interestingly, digalactosyl diacylglycerols have been reported to constitute major membrane lipid components in bacteroid forms of Bradyrhizobium japonicum (Tang and Hollingsworth 1997). Another diglycosyl diacylglycerol was isolated from Rhizobium leguminosarum bv. trifolii ANU843 and its covalent structure was reported to be 1,2-diacyl-3- $O$-( $\alpha$-D-glucopyranosyl-(1-3)- $O$ $\alpha$-D-mannopyranosyl)-glycerol (Orgambide et al. 1994). However, so far little is known about the biosynthesis of glycolipids in gram-negative bacteria or the genes involved.

\section{Sulfolipids.}

The sulfolipid sulfoquinovosyl diacylglycerol occurs widely in photosynthetic organisms ranging from bacteria to seed plants (Benning 1998), where it is associated with photosynthetic membranes. Although sulfolipid generally is not essential for photosynthesis, it is required for growth under phosphate-limiting growth conditions in Rhodobacter sphaeroides and cyanobacteria (Benning et al. 1993; Güler et al. 1996). In Rhodobacter sphaeroides, phosphate limitation of the wild type caused a significant reduction in the amount of all phos-

Table 2. Bacteria containing open reading frames (ORFs) probably involved in phosphorous free membrane lipid biosynthesis ${ }^{\mathrm{a}}$

\begin{tabular}{|c|c|c|c|c|}
\hline \multirow[b]{2}{*}{ Organism $^{\text {b }}$} & \multicolumn{4}{|c|}{ Query (number of amino acids) } \\
\hline & $\begin{array}{c}\text { SqdB (406) } \\
\text { Sinorhizobium meliloti }\end{array}$ & $\begin{array}{l}\text { OlsA (292) } \\
\text { S. meliloti }\end{array}$ & $\begin{array}{c}\text { BtaA (416) } \\
\text { Rhodobacter sphaeroides }\end{array}$ & $\begin{array}{c}\text { SqhC (660) } \\
\text { Bradyrhizobium. japonicum }\end{array}$ \\
\hline \multicolumn{5}{|l|}{ Proteobacteria } \\
\hline \multicolumn{5}{|l|}{$\alpha$-Subdivision } \\
\hline Agrobacterium tumefaciens ${ }^{\mathrm{c}}$ & $\ldots$ & $2 \times 10^{-88}$ & $10^{-107}$ & $\ldots$ \\
\hline Bradyrhizobium japonicum $^{\mathrm{c}}$ & $\ldots$ & $\ldots$ & $\ldots$ & $* 0.0$ \\
\hline Brucella melitensis $^{\mathrm{c}}$ & $\ldots$ & $8 \times 10^{-68}$ & & $\ldots$ \\
\hline Mesorhizobium loti MAFF303099 & $\ldots$ & $5 \times 10^{-67}$ & $10^{-112}$ & $\ldots$ \\
\hline Rhizobium leguminosarum ${ }^{\mathrm{u}}$ & 0.0 & $7 \times 10^{-96}$ & $10^{-102}$ & $\ldots$ \\
\hline Rhizobium sp. NGR234 $4^{\mathrm{pc}}$ & $\ldots$ & $\ldots$ & $\ldots$ & 0.0 \\
\hline Rhodobacter sphaeroides $\mathrm{u}^{\mathrm{u}}$ & $* 0.0$ & $9 \times 10^{-18}$ & $* 0.0$ & $\ldots$ \\
\hline Rhodopseudomonas palustris ${ }^{\mathrm{u}}$ & $\ldots$ & $5 \times 10^{-57}$ & $2 \times 10^{-83}$ & 0.0 \\
\hline Sinorhizobium meliloti $^{\mathrm{c}}$ & $* 0.0$ & $* 10^{-166}$ & $10^{-107}$ & $\ldots$ \\
\hline \multicolumn{5}{|l|}{$\beta$-Subdivision } \\
\hline Burkholderia fungorum ${ }^{u}$ & $\ldots$ & $4 \times 10^{-24}$ & $\ldots$ & 0.0 \\
\hline Ralstonia solanacearum ${ }^{\mathrm{c}}$ & $\ldots$ & $1 \times 10^{-19}$ & $\ldots$ & $\ldots$ \\
\hline \multicolumn{5}{|l|}{$\lambda$-Subdivision } \\
\hline Escherichia coli ${ }^{\mathrm{c}}$ & $\ldots$ & $\ddot{r}$ & $\ldots$ & $\ldots$ \\
\hline Methylococcus capsulatus ${ }^{\mathrm{u}}$ & $\ldots$ & $1 \times 10^{-23}$ & $\ldots$ & $10^{-179}$ \\
\hline Pseudomonas aeruginosa ${ }^{\mathrm{c}}$ & $\ldots$ & $2 \times 10^{-19}$ & $\ldots$ & $\ldots$ \\
\hline Pseudomonas fluorescens ${ }^{\mathrm{u}}$ & $\ldots$ & $3 \times 10^{-16}$ & $\ldots$ & $\ldots$ \\
\hline \multicolumn{5}{|l|}{ Cyanobacteria } \\
\hline Nostoc puntiforme $e^{\mathrm{u}}$ & $9 \times 10^{-85}$ & $\ldots$ & $\ldots$ & $10^{-118}$ \\
\hline Synechococcus sp. WH $8102^{\mathrm{u}}$ & $10^{-142}$ & $\ldots$ & $\ldots$ & $\ldots$ \\
\hline Prochlorococcus marinus ${ }^{\mathrm{u}}$ & $10^{-145}$ & $\ldots$ & $\ldots$ & $\ldots$ \\
\hline \multicolumn{5}{|l|}{ Firmicutes } \\
\hline Streptomyces coelicolor ${ }^{\mathrm{c}}$ & $\ldots$ & $3 \times 10^{-18}$ & $\ldots$ & $10^{-127}$ \\
\hline Bacillus subtilis ${ }^{\mathrm{c}}$ & $\ldots$ & $\ldots$ & $\ldots$ & $8 \times 10^{-63}$ \\
\hline \multicolumn{5}{|l|}{ Archaea } \\
\hline Thermoplasma acidophilum ${ }^{\mathrm{c}}$ & $3 \times 10^{-60}$ & $\ldots$ & $\ldots$ & $\ldots$ \\
\hline Sulfolobus tokodaii ${ }^{\mathrm{c}}$ & $4 \times 10^{-62}$ & $\ldots$ & $\ldots$ & $\ldots$ \\
\hline \multicolumn{5}{|l|}{ Eukaryotes } \\
\hline Arabidopsis thaliana $^{\mathrm{n}}$ & $* 5 \times 10^{-81}$ & $\ldots$ & $\cdots$ & $\ldots$ \\
\hline Candida albicans $\mathrm{u}^{\mathrm{u}}$ & $\ldots$ & $\ldots$ & $5 \times 10^{-17}$ & $\ldots$ \\
\hline Aspergillus fumigatus $^{\mathrm{u}}$ & $\ldots$ & $\ldots$ & $2 \times 10^{-8}$ & $\ldots$ \\
\hline
\end{tabular}

${ }^{a}$ Expect (E) values obtained for the deduced ORFs using the indicated queries. E values were obtained using the BLOSUM62 matrix and the program TBLASTN 2.2.5.

${ }^{\mathrm{b}} \mathrm{c}=$ Completed genome sequence, $\mathrm{u}=$ unfinished genome sequence, $\mathrm{n}=$ not from a genome project, $\mathrm{pc}=\mathrm{complete}$ sequence of the symbiotic plasmid. An asterisk (*) precedes numbers for ORFs that have been demonstrated to be required for the biosynthesis of the respective membrane lipid. 
pholipids and an increased amount of sulfolipid. This sulfolipid, 6-sulfo- $\alpha$-D-quinovosyl diacylglycerol, has been suggested to function as a surrogate for phospholipids, particularly phosphatidylglycerol, under phosphate-limiting conditions (Benning et al. 1993). At least four structural genes ( $s q d A$, $s q d B, s q d C$, and $s q d D)$ are involved in sulfolipid biosynthesis in Rhodobacter sphaeroides (Benning 1998).

The most highly conserved sulfolipid gene in bacteria, $s q d B$, and its ortholog in plants, $S Q D 1$, encode for an enzyme involved in the biosynthesis of UDP-sulfoquinovose from UDP-glucose and sulfite as a sulfur donor (Sanda et al. 2001). Although the function of the bacterial $s q d A$ gene in sulfolipid biosynthesis remains unclear, $s q d C$ and $s q d D$ are thought to catalyze the transfer of sulfoquinovose from UDP-sulfoquinovose to diacylglycerol (DAG) (Benning 1998; Yu et al. 2002). A model for sulfolipid biosynthesis in bacteria is presented in Figure 2.

Sulfoquinovosyl diacylglycerol also is present in some nonphotosynthetic bacteria (Benning 1998) (i.e., in some members of the Rhizobiaceae, such as S. meliloti, Rhizobium leguminosarum, and Rhizobium NGR234 (Cedergren and Hollingsworth 1994). The fact that sulfolipids were absent in Agrobacterium spp. and $E$. coli led to the proposal that sulfolipids might be an essential requirement for the establishment of the nitrogen-fixing root nodule symbiosis between rhizobia and their legume host plants (Cedergren and Hollingsworth 1994). However, a sulfolipid-deficient mutant of $S$. meliloti disrupted in $s q d B$ is capable of inducing functional nodules and does not show an obvious disadvantage under different laboratory culture conditions (Weissenmayer et al. 2000).

Good homologues of the sinorhizobial $s q d B$ gene product are found in $R$. leguminosarum, Rhodobacter sphaeroides, the cyanobacteria Nostoc puntiforme, Synechococcus, Prochlorococcus marinus, as well as Arabidopsis thaliana genomes
(Table 2), all of them organisms known for their ability to synthesize SL. Good SqdB homologues also are found in the archaea Thermoplasma and Sulfolobus (Table 2) and, based on these data, we expect that the $s q d B$-encoded enzymatic function exists in these organisms and that they might form UDPsulfoquinovose. We expect, however, that UDP-sulfoquinovose in archaea is not used for SL biosynthesis but for other biosynthetic purposes. The $s q d B$ gene is absent in Agrobacterium tumefaciens, Brucella melitensis, Bradyrhizobium japonicum, and Mesorhizobium loti, suggesting that none of these organisms can form SL and, in the cases of M. loti and B. japonicum, proving once more that bacterial SL is not required for the establishment of a nitrogen-fixing root nodule symbiosis with a legume host. From this rather limited occurrence of $s q d B$ in bacterial genomes, one might conclude that SL is formed in only a few bacteria.

\section{Ornithine-derived lipids.}

OL are widespread among gram-negative bacteria (Asselineau 1991; Ratledge and Wilkinson 1988) and have been reported in some gram-positive bacteria, such as Mycobacterium and Streptomyces spp. (Lanéelle et al. 1990). Also, in some clinical Flavobacterium (Kawai et al. 1988) and Burkholderia (Phung et al. 1995) isolates, OL have been reported as a major lipid fraction and might be essential for the pathogenicity of such bacteria. Considering the broad distribution of OL in bacteria, it is surprising that, until recently, neither their biosynthesis nor any genes or enzymes involved were known.

Furthermore, some bacterial lipids are well-known to cause very drastic reactions when getting in contact with eukaryotes. The best studied example of that kind is the bacterial endotoxin lipid A; its role on eukaryotes as well as its biosynthesis has been studied in some detail (Raetz and Whitfield 2002). Like lipid A, OL possess an amidified 3-hydroxyfatty acyl group that is further

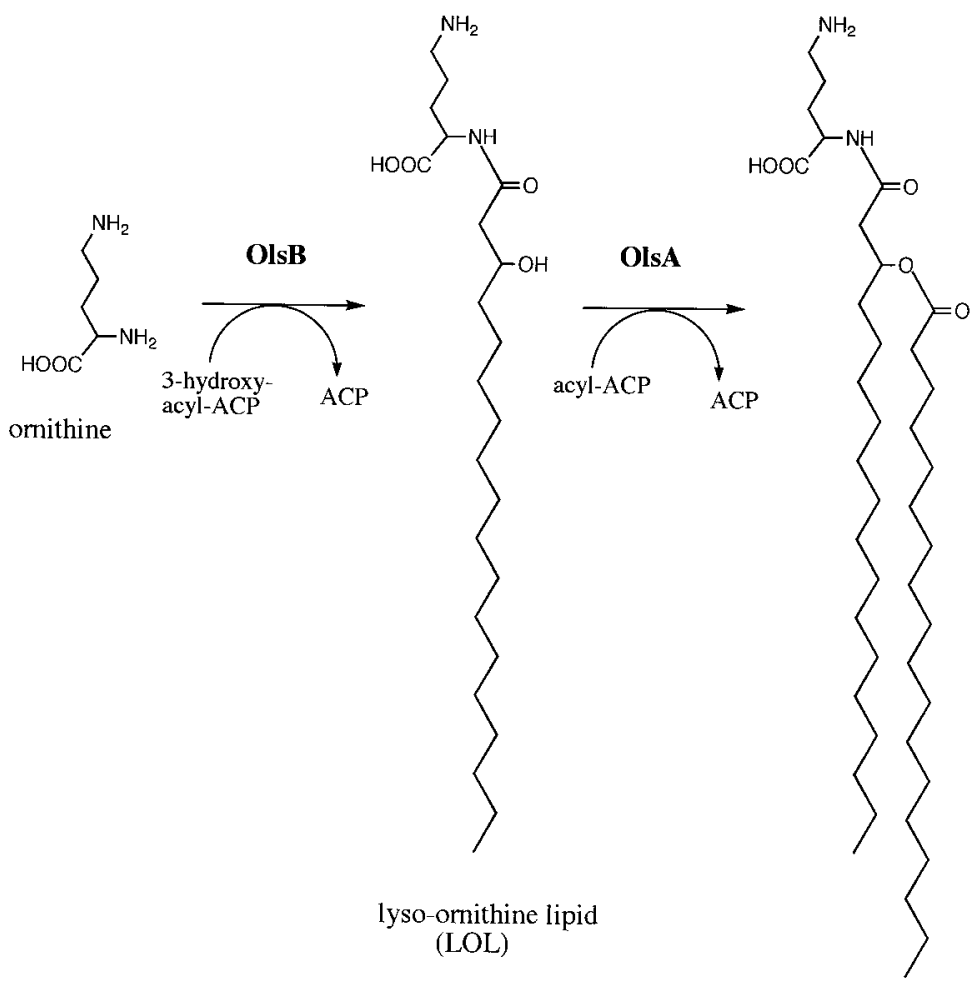

ornithine lipid

(OL)

Fig. 3. Model for the biosynthesis of ornithine-derived lipids (OL) in bacteria. 
esterified through its hydroxy with another fatty acyl residue. Also, like lipid A, OL seems to be predominantly localized in the outer membrane (Dees and Shively 1982). However, whereas most lipid A molecules are quite toxic, OL seem to be nontoxic, cause B-cell mitogenicity, function as strong stimulants for macrophages to generate interleukin-1 and prostaglandin E2, and can be used as adjuvants (Kato and Goto 1997; Kawai et al. 1999). OL applied to mice before the endotoxin lipid A can even prevent the lethal effects of the latter and it has been suggested that, because of the structural similarities between the two types of molecules, OL might function as an antagonistic blocker of lipid A-provoked events (Kawai et al. 1991).

The structures of OL have been described from a number of organisms and were found to be an $\alpha$ - $N$-(acyloxyacyl)ornithine (Knoche and Shively 1972). In this structure, a 3hydroxyfatty acyl group is attached as an amide to the $\alpha$-amino group of ornithine. A second fatty acyl group is linked as an ester to the 3-hydroxy position of the first fatty acid. A similar structure has been described for the OL from $S$. meliloti (Fig. 3). Consequently, for the biosynthesis of such a compound, minimally two steps are required; therefore, one would expect at least two distinct enzymatic activities. One enzyme should be required for the formation of the amide linkage ( $N$-acyltransferase) between the $\alpha$-amino group of ornithine and the carboxyl group of the 3-hydroxyfatty acid and, most likely, a different one should be responsible for forming the ester linkage ( $O$-acyltransferase) between the 3-hydroxy group of the first fatty acyl group and the carboxy of the second fatty acid. Therefore, for ornithine lipid biosynthesis, at least two structural genes should be required.

Recently, the isolation of mutants of Sinorhizobium meliloti deficient in the biosynthesis of OL was described (Weissenmayer et al. 2002). Complementation of such mutants with a sinorhizobial cosmid gene bank, subcloning of the complementing fragment, and sequencing of the subclone led to the identification of a gene (olsA) coding for a presumptive acyltransferase. Amplification of this gene and its expression in OL-deficient mutant backgrounds of $S$. meliloti demonstrates that it is required for OL biosynthesis. An OLdeficient mutant of $S$. meliloti disrupted in olsA shows wild type-like growth behavior and is capable of inducing nitrogen-fixing nodules on legume hosts. A lyso-ornithine lipiddependent acyl transferase activity forming OL requires acylAcpP as the acyl donor and expression of the olsA gene. Therefore OlsA catalyzes the second step in OL biosynthesis (Fig. 3).
OL are widespread in bacteria, and good homologues of the OlsA protein can be assigned in many recently sequenced bacterial genomes (Table 2); therefore, it probably is fair to assume that OL frequently are found among the common membrane lipids in many eubacteria. Notably, we did not find OlsA homologues in eukaryotic or archaeal genome sequences, suggesting that, although widespread within the eubacteria, OL also are limited to the eubacterial group.

In some bacteria, such as Burkholderia cepacia (Taylor et al. 1998) or Flavobacterium sp. (Asselineau 1991), besides the OL mentioned above, OL exist in which the ester-linked fatty acyl group possesses a hydroxyl group at the 2-position. Similar S-2-hydoxyfatty acyl moieties are integral parts of Salmonella typhimurium lipid A and are thought to be of importance for pathogenesis of this organism. The S-2-hydroxylation is introduced after the fatty acyl group had been attached to the lipid A molecule and is catalyzed by LpxO, a new dioxygenase (Gibbons et al. 2000). A similar dioxygenase might be responsible for the introduction of 2-hydroxy substitutions on the ester-linked fatty acyl group of OL. Whether such 2-hydroxy substitutions on the ester-linked fatty acyl group of OL contribute in any way to potential interactions with eukaryotic hosts has not been studied so far.

\section{Diacylglyceryl- $N, N, N$-trimethylhomoserine lipids.}

Although PC is known to be the major membrane lipid in eukaryotes, some lower eukaryotic organisms possess the betaine lipid DGTS instead. DGTS occurs in a wide variety of lower green plants (green algae, bryophytes, and pteridophytes), chromophytes, fungi, and amoebae (Sohlenkamp et al. 2003). There is an apparent reciprocity between the content of PC and the content of DGTS (i.e., when PC is a major membrane lipid, often no DGTS is detected in the same organism; whereas, in organisms where DGTS is a major lipid, PC is found only in trace levels). This suggests that DGTS and PC, both zwitterionic at physiological $\mathrm{pH}$, are interchangeable, at least with regard to essential functions for the respective organism.

In prokaryotes, DGTS has been identified as a phosphorusfree membrane lipid that substitutes for PC under conditions of phosphate limitation (Benning et al. 1995; Geiger et al. 1999; Hofmann and Eichenberger 1996). Under phosphorus limitation, PC is nearly quantitatively replaced by DGTS in $S$. meliloti (Geiger et al. 1999), suggesting that, under such conditions, DGTS is taking over many functions that are usually performed by $\mathrm{PC}$ in phosphorus-rich conditions. Especially, DGTS is expected to substitute well for PC in physicochemical

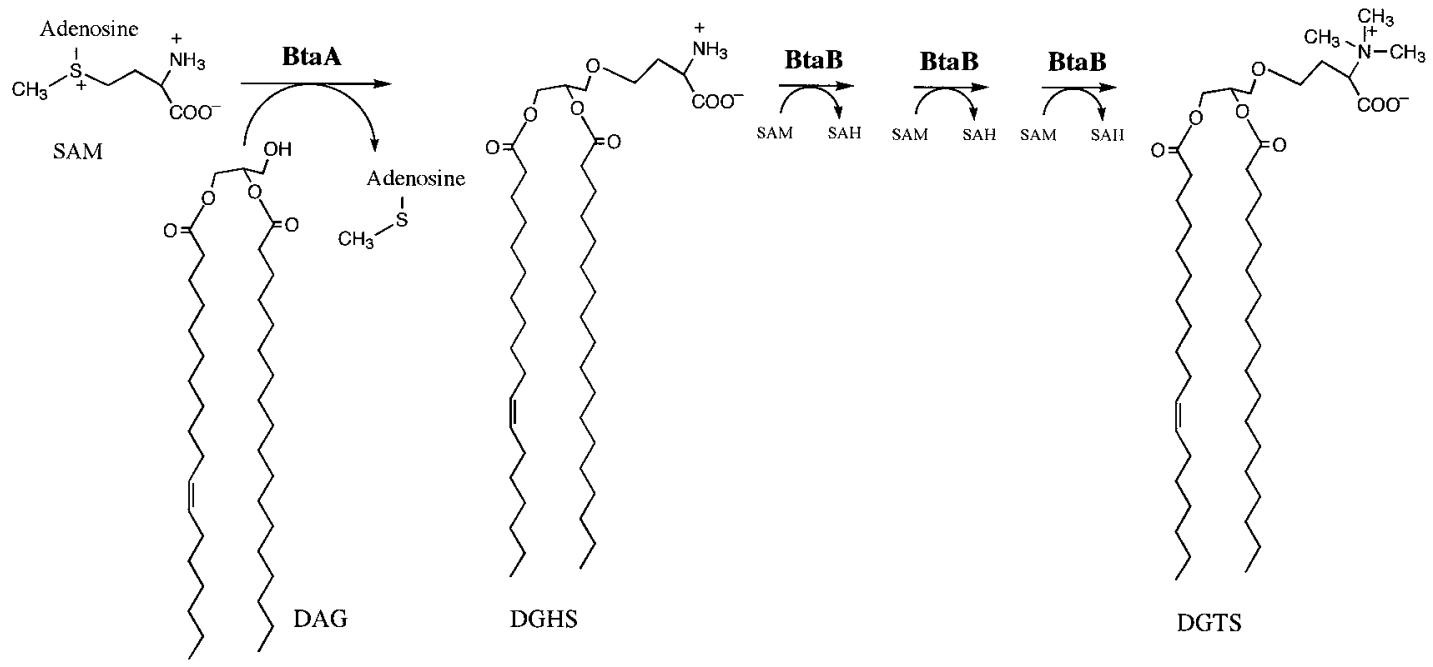

Fig. 4. Model for the biosynthesis of diacylglyceryl- $N, N, N$-trimethyl homoserine (DGTS). DAG = diacylglycerol; DGHS = diacylglyceryl homoserine. 
terms (i.e., in lipid bilayer formation). If there are, however, specific functions for which the PC molecule per se is required, one might expect that DGTS is not functional in this context.

Recently, the $b t a A B$ genes coding for two enzymes involved in DGTS biosynthesis have been cloned from Rhodobacter sphaeroides (Klug and Bennning 2001). The btaA gene product reveals weak similarity to a bacterial methyltransferase and to other proteins of unknown function and is involved in the first step of DGTS biosynthesis, whereas the $b t a B$ gene product clearly is a homologue of SAM-dependent methyltransferases. Homologues to BtaA and BtaB have been detected only in the bacterial genomes of S. meliloti, Rhizobium leguminosarum, Mesorhizobium loti, A. tumefaciens, and Rhodopseudomonas palustris, as well as some "weaker" homologues in the fungal genomes of Candida and Aspergillus (Table 2), suggesting that the ability to form DGTS within the bacteria might be limited to some members of the $\alpha$-proteobacteria. The enzymatic activities of the $b t a A$ and $b t a B$ gene products have not been established yet, but Klug and Benning (2001) speculated that the btaA gene product is an $S$-adenosylmethionine:diacylglycerol 3-amino-3-carboxypropyl transferase probably catalyzing the ether formation between DAG and a homoserine residue, which is presumably derived from SAM. BtaB might function as an $S$-adenosylmethionine: diacylglycerylhomoserine- $N$-methyltransferase which is catalyzing the threefold methylation of diacylglyceride homoserine using SAM as the donor of the methyl groups (Fig. 4). Expression of the bta genes and, consequently, DGTS formation in PC-deficient mutants of $S$. meliloti will make it testable to what extent DGTS can restore PC-provoked defects.

\section{Hopanoid lipids.}

Hopanoids are a class of pentacyclic triterpenoid lipids occurring predominantly in some bacteria. Like cholesterol in eukaryotes, they are thought to comprise a class of membrane stabilizers important for the proper functioning of the bacterial cell membrane. Hopanoids are found in a wide range of gramnegative and gram-positive bacteria and have been described in the nitrogen-fixing Azotobacter and Beijerinckia bacteria as well as in symbiotic nitrogen-fixing Frankia and Bradyrhizobium (Kannenberg et al. 1995) bacteria. Bradyrhizobia contain the triterpenoids hopene, diplopterol, the methylated derivatives thereof, elongated forms of hopanoids, as well as squalene, the biosynthetic precursor in hopanoid biosynthesis (Fig. 5). The gene encoding a key enzyme of hopanoid biosynthesis, squalene-hopene cyclase (SHC, SqhC), has been cloned from Bradyrhizobium japonicum (Perzl et al. 1997). Upon expression of the $s q h C$ gene in $E$. coli, the recombinant enzyme is able to catalyze the cyclization of squalene to hopanoid derivatives in vitro. Good to very good homologues of the bradyrhizobial SqhC are found in many eubacterial genomes (Table 2) but seem to be absent in eukaryotes and archaea, suggesting that hopanoids are frequent ingredients of eubacterial membranes. In some bradyrhizobia, hopanoids can make up to $50 \%$ of the total lipid fraction. However, no triterpenoids have been detected in representatives of the genus Rhizobium (Kannenberg et al. 1995). Although a very good homologue of SqhC is found in the symbiotic plasmid of Rhizobium sp. NGR234, no homologues are detected in the genomes of S. meliloti, R. leguminosarum, and $M$. loti, suggesting that these microsymbionts cannot form hopanoids and that, consequently, bacterial hopanoids cannot be an essential requirement for all rhizobia in their ability to form a nitrogen-fixing root nodule symbiosis with their respective legume host.

In Frankia spp., nitrogen fixation occurs within specialized multicellular structures termed vesicles. A vesicle is surrounded by a multilamellate, lipid-containing envelope that apparently functions as a barrier to oxygen diffusion. The envelope consists primarily of two hopanoid lipids, bacteriohopanetetrol and bacteriohopanetetrol phenylacetate monoester, the latter of which is vesicle-specific (Berry et al. 1993). Partial sequences from different Frankia strains that show homology to the bradyrhizobial SqhC have been identified (Dobritsa et al.

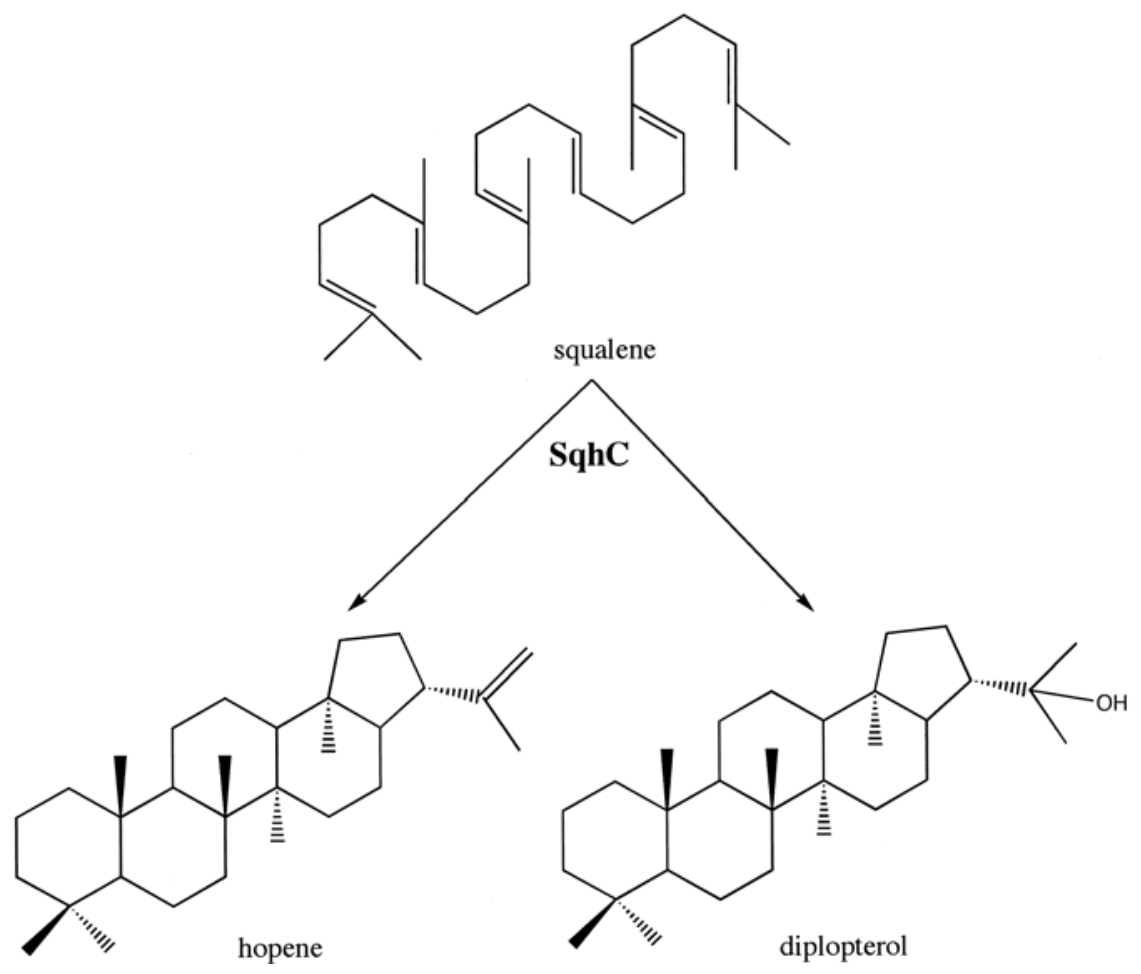

Fig. 5. Enzymic cyclization of squalene. Hopene and diplopterol are formed in prokaryotes from squalene by SqhC activity. Elimination of a proton leads to hopene; addition of a hydroxyl group derived from water leads to formation of diplopterol. 
2001), suggesting that hopanoid biosynthesis in Frankia spp. also occurs via a SqhC activity. As in Frankia spp., bradyrhizobia hopanoids might play a role in the adaptation to microaerobic conditions. They might be involved in other mechanisms of cell adaptation, such as increasing the resistance of bradyrhizobia to acidic growth conditions. This assumption is supported indirectly by the finding that the amount of hopanoid lipids in the thermoacidophilic bacterium Alicyclobacillus (formerly Bacillus) acidocaldarius increases in response to decreasing $\mathrm{pH}$ values in the culture medium. Clearly, to define the exact role of hopanoids in bradyrhizobia, the isolation of hopanoid-deficient mutants and a thorough characterization of their respective phenotypes is needed.

\section{Conclusions and perspectives.}

Biosynthesis of membrane lipids in plant-associated bacteria is more complex than anticipated. In addition to the major membrane lipids detected in E. coli, phosphatidylglycerol, cardiolipin, and PE, in plant-associated bacteria frequently the trimethylated derivative of $\mathrm{PE}$, phosphatidylcholine is encountered. Many plant-associated bacteria possess two pathways for the biosynthesis of PC, the methylation pathway and the PC synthase pathway. For the methylation pathway, there are at least two classes of Pmt enzymes which probably are derived from different origins. Although the Rhodobacter Pmt type shows homology to UbiE (Ubiquinone/menaquinone biosynthesis methyltransferase), the Sinorhizobium Pmt type shows homology to rRNA methylases. In addition to the methylation pathway, there exists a novel pathway for PC biosynthesis in prokaryotes. This novel pathway uses choline but is different from the eukaryotic CDP-choline pathway, and involves a new enzymatic activity, Pcs, that directly condenses CDP-diacylglycerol and choline.

The novel Pcs activity enables bacteria to produce PC from exogenous choline provided by the eukaryotic organism with which they associate. A similar mechanism, the use of choline as building block for the biosynthesis of membrane lipids, is shared between symbiotic (S. meliloti, Rhizobium leguminosarum, M. loti, Bradyrhizobium japonicum) and saprophytic (Rhodobacter sphaeroides, Rhodopseudomonas palustris) bacteria as well as between bacterial pathogens of plants (A. tumefaciens and $P$. syringae) or animals or humans ( $P$. aeruginosa, Legionella pneumophila, Borrelia burgdorferi). Clearly, the choline provided by eukaryotes in body fluids or root exudates must originate from phospholipase C- or phospholipase Dcatalyzed reactions. It is interesting to note that both phospholipase $\mathrm{C}$ and phospholipase $\mathrm{D}$ activities of host plants are activated by rhizobial nodulation factors (den Hartog et al. 2001) and that, in such cases, levels of choline should be formed which are well above those encountered in root exudates from plants that have not been challenged with a bacterial microsymbiont. Choline provided by eukaryotes as a building block for an easier biosynthesis of the membrane lipid PC might indicate a more general concept in the molecular interactions between bacteria and their eukaryotic hosts. For example, many soil bacteria form phosphorus-free membrane lipids (glycolipids, sulfolipids, ornithine-derived lipids, homoserinederived lipids, and hopanoids), and some of these lipids are formed predominantly under growth conditions where phosphorus sources are limiting. Also, each one of these phosphorus-free lipid classes show a characteristic distribution within certain different bacterial clades. S. meliloti forms two membrane lipids, OL and DGTS, which contain the nonproteinogenic amino acid ornithine or homoserine as structural components, respectively. Interestingly, ornithine and homoserine are among the predominant amino acids in pea root exudate (Boulter et al. 1966) and the question arises whether OL or DGTS can be formed by direct incorporation of the amino acids ornithine or homoserine (i.e., whether also in the case of the membrane lipids OL and DGTS, simpler biosynthesis pathways can be used when the adequate building blocks are provided by the eukaryotic host).

\section{ACKNOWLEDGMENTS}

Work in our laboratory was supported by grants from DGAPA/UNAM (IN207200), CONACyT-Mexico (33577-N and 36274-N), UC MEXUSCONACyT, and the Howard Hughes Medical Institute (HHMI 55003675). C. Sohlenkamp is a Feodor Lynen Fellow of the Alexander von Humboldt Foundation, Bonn, Germany.

\section{LITERATURE CITED}

Arondel, V., Benning, C., and Somerville, C. R. 1993. Isolation and functional expression in Escherichia coli of a gene encoding phosphatidylethanolamine methyltransferase (EC 2.1.1.17) from Rhodobacter sphaeroides. J. Biol. Chem. 268:16002-16008.

Asselineau, J. 1991. Bacterial lipids containing amino acids or peptides linked by amide bonds. Fortschr. Chem. Org. Naturst. 56:1-85.

Benning, C. 1998. Biosynthesis and function of the sulfolipid sulfoquinovosyl diacylglycerol. Annu. Rev. Plant Physiol. Plant Mol. Biol. 49:53-75.

Benning, C., Beatty, J. T., Prince, R. C., and Somerville, C. R. 1993. The sulfolipid sulfoquinovosyldiacylglycerol is not required for photosynthetic electron transport in Rhodobacter sphaeroides but enhances growth under phosphate limitation. Proc. Natl. Acad. Sci. U.S.A. 90:1561-1565.

Benning, C., Huang, Z.-H., and Gage, D. A. 1995. Accumulation of a novel glycolipid and a betaine lipid in cells of Rhodobacter sphaeroides grown under phosphate limitation. Arch. Biochem. Biophys. 317:103-111.

Berry, A. M., Harriott, O. T., Moreau, R. A., Osman, S. F., Benson, D. R., and Jones, A. D. 1993. Hopanoid lipids compose the Frankia vesicle envelope, presumptive barrier of oxygen diffusion to nitrogenase. Proc. Natl. Acad. Sci. U.S.A. 90:6091-6094.

Boulter, D., Jeremy, J. J., and Wilding, M. 1966. Amino acids liberated into the culture medium by pea seedling roots. Plant Soil 14:17061713.

Bunn, C. R., and Elkan, G. H. 1971. The phospholipid composition of Rhizobium japonicum. Can. J. Microbiol. 17:291-295.

Bunn, C. R., McNeill, J. J., and Elkan, G. H. 1970. Effect of biotin on fatty acids and phospholipids of biotin-sensitive strains of Rhizobium japonicum. J. Bacteriol. 102:24-29.

Cedergren, R. A., and Hollingsworth, R. I. 1994. Occurrence of sulfoquinovosyl diacylglycerol in some members of the family Rhizobiaceae. J. Lipid Res. 35:1452-1461.

Chan, E. C., Chang, C. C., Li, Y. S., Chang, C. A., Chiou, C. C., and Wu, T. Z. 2000. Purification and characterization of neutral sphingomyelinase from Helicobacter pylori. Biochemistry 39:4838-4845.

Cronan, J. E. 2002. Phospholipid modifications in bacteria. Curr. Opin. Microbiol. 5: 202-205.

Dees, C., and Shively, J. M. 1982. Localization and quantitation of the ornithine lipid of Thiobacillus thiooxidans. J. Bacteriol. 149:798-799.

den Hartog, M., Musgrave, A., and Munnik, T. 2001. Nod factor-induced phosphatidic acid and diacylglycerol pyrophosphate formation: a role for phospholipase C and D in root hair deformation. Plant J. 25:55-65.

de Rudder, K. E. E., López-Lara, I. M., and Geiger, O. 2000. Inactivation of the gene for phospholipid $N$-methyltransferase in Sinorhizobium meliloti: Phosphatidylcholine is required for normal growth. Mol. Microbiol. 37:763-772.

de Rudder, K. E. E., Sohlenkamp, C., and Geiger, O. 1999. Plant-exuded choline is used for rhizobial membrane lipid biosynthesis by phosphatidylcholine synthase. J. Biol. Chem. 274:20011-20016.

de Rudder, K. E. E., Thomas-Oates, J. E., and Geiger, O. 1997. Rhizobium meliloti mutants deficient in phospholipid $N$-methyltransferase still contain phosphatidylcholine. J. Bacteriol. 179:6921-6928.

Dobritsa, S. V., Potter, D., Gookin, T. E., and Berry, A. M. 2001. Hopanoid lipids in Frankia: identification of squalene-hopene cyclase gene sequences. Can. J. Microbiol. 47:535-540.

Dowhan, W., and Bogdanov, M. 2002. Functional roles of lipids in membranes. Pages 1-35 in: Biochemistry of Lipids, Lipoproteins and Membranes, 4th ed. D. E. Vance and J. E. Vance, eds. Elsevier, Amsterdam, The Netherlands.

Geiger, O. 1998. Phospholipids and alternative membrane lipids. Pages 55-80 in: The Rhizobiaceae. Molecular Biology of Model Plant-Asso- 
ciated Bacteria. H. P. Spaink, A. Kondorosi, and P. J. J. Hooykaas, eds. Kluwer Academic Publishers, Dordrecht, The Netherlands.

Geiger, O., Röhrs, V., Weissenmayer, B., Finan, T. M., and ThomasOates, J. E. 1999. The regulator gene $p h o B$ mediates phosphate stresscontrolled synthesis of the membrane lipid diacylglyceryl- $N, N, N$ trimethylhomoserine in Rhizobium (Sinorhizobium) meliloti. Mol. Microbiol. 32:63-73.

Gerson, T., and Patel, J. J. 1975. Neutral lipids and phospholipids of freeliving and bacteroid forms of two strains of Rhizobium infective on Lotus pedunculatus. Appl. Microbiol. 30:193-198.

Gibbons, H. S., Lin, S., Cotter, R. J., and Raetz, C. R. H. 2000. Oxygen requirement for the biosynthesis of the $S$-2-hydroxymyristate moiety in Salmonella typhimurium lipid A. J. Biol. Chem. 275:32940-32949.

Gill, C. O. 1975. Effect of growth temperature on the lipids of Pseudomonas fluorescens. J. Gen. Microbiol. 89:293-298.

Glenn, A. R., Reeve, W. G., Tiwari, R. P., and Dilworth, M. J. 1999. Acid tolerance in root nodule bacteria. Novartis Found. Symp. 221:112-130.

Goldfine, H. 1982. Lipids of procaryotes-Structure and distribution. Pages 1-43 in: Current Topics in Membranes and Transport, vol. 17. S Razin and S. Rottem, eds. Academic Press, New York.

Güler, S., Seliger, S., Hartel, H., Renger, G., and Benning, C. 1996. A null mutant of Synechococcus sp. PCC7942 deficient in the sulfolipid sulfoquinovosyl diacylglycerol. J. Biol. Chem. 271:7501-7507.

Hanada, T., Kashima, Y., Kosugi, A., Koizumi, Y., Yanagida, F., and Udaka, S. 2001. A gene encoding phosphatidylethanolamine N-methyltransferase from Acetobacter aceti and some properties of its disruptant. Biosci. Biotechnol. Biochem. 65:2741-2748.

Haydock, S. F., Dowson, J. A., Dhillon, N., Roberts, G. A., Cortes, J., and Leadlay, P. F. 1991. Cloning and sequence analysis of genes involved in erythromycin biosynthesis in Saccharopolyspora erythraea: Sequence similarities between EryG and a family of $S$-adenosylmethionine-dependent methyltransferases. Mol. Gen. Genet. 230:120-128.

Heath, R. J., Jackowski, S., and Rock, C. O. 2002. Fatty acid and phospholipid metabolism in prokaryotes. Pages 55-92 in: Biochemistry of Lipids, Lipoproteins and Membranes, 4th ed. D. E. Vance and J. E. Vance, eds. Elsevier, Amsterdam, The Netherlands.

Hofmann, M., and Eichenberger, W. 1996. Biosynthesis of diacylglyceryl- $N, N, N$-trimethylhomoserine in Rhodobacter sphaeroides and evidence for lipid-linked N methylation. J. Bacteriol. 178:6140-6144.

Ingrosso, D., Fowler, A. V., Bleibaum, J., and Clarke, S. 1989. Sequence of the D-aspartyl/L-isoaspartyl protein methyltransferase from human erythrocyte. J. Biol. Chem. 264:20131-20139.

Jackson, M., Crick, D. C., and Brennan, P. J. 2000. Phosphatidylinositol is an essential phospholipid in mycobacteria. J. Biol. Chem. 275:30092-30099.

Kaneshiro, T., and Law, J. H. 1964. Phosphatidylcholine synthesis in Agrobacterium tumefaciens. I. Purification and properties of a phosphatidylethanolamine $N$-methyltransferase. J. Biol. Chem. 239:17051713.

Kannenberg, E. L., Perzl, M., and Hartner, T. 1995. The occurrence of hopanoid lipids in Bradyrhizobium bacteria. FEMS (Fed. Eur. Microbiol. Soc.) Microbiol. Lett. 127:255-262.

Kannenberg, E. L., Reuhs, B. L., Forsberg, L. S., and Carlson, R. W. 1998. Lipopolysaccharides and K-antigens: Their structures, biosynthesis and functions. Pages 119-154 in: The Rhizobiaceae. Molecular Biology of Model Plant-Associated Bacteria. H. P. Spaink, A. Kondorosi, and P. J. J. Hooykaas, eds. Kluwer Academic Publishers, Dordrecht, The Netherlands.

Karnezis, T., Fisher, H. C., Neumann, G. M., Stone, B. A., and Stanisich, V. A. 2002. Cloning and characterization of the phosphatidylserine synthase gene of Agrobacterium sp. strain ATCC 31749 and effect of its inactivation on production of high-molecular-mass (1-3)-b-D-glucan (curdlan). J. Bacteriol. 184:4114-4123

Kato, H., and Goto, N. 1997. Adjuvanticity of an ornithine-containing lipid of Flavobacterium meningosepticum as a candidate vaccine adjuvant. Microbiol. Immunol. 41:101-106.

Kawai, Y., Kaneda, K., Morisawa, Y., and Akagawa, K. 1991. Protection of mice from lethal endotoxemia by use of an ornithine-containing lipid or a serine-containing lipid. Infect. Immun. 59:2560-2566.

Kawai, Y., Nakagawa, Y., Matuyama, T., Akagawa, K., Itagawa, K., Fukase, K., Kusumoto, S., Nishijima, M., and Yano, I. 1999. A typical bacterial ornithine-containing lipid N-(D)-3-(hexdecanoyloxy)hexadecanoyl-ornithine is a strong stimulant for macrophages and a useful adjuvant. FEMS (Fed. Eur. Microbiol. Soc.) Immunol. Med. Microbiol. 23:67-73.

Kawai, Y., Yano, I., and Kaneda, K. 1988. Various kinds of lipoamino acids including a novel serine-containing lipid in an opportunistic pathogen Flavobacterium. Eur. J. Biochem. 171:73-80.

Kent, C. 1995. Eukaryotic phospholipid biosynthesis. Annu. Rev. Biochem. 64:315-343.
Klug, R. M., and Benning, C. 2001. Two enzymes of diacylglycerol-O-4'$(N, N, N$,-trimethyl)-homoserine biosynthesis are encoded by btaA and btaB in the purple bacterium Rhodobacter sphaeroides. Proc. Natl. Acad. Sci. U.S.A. 98:5910-5915.

Knoche, H. W., and Shively, J. M. 1972. The structure of an ornithinecontaining lipid from Thiobacillus thiooxydans. J. Biol. Chem. 247:170-178

Lanéelle, M.-A., Promé, D., Lanéelle, G., and Promé, J.-C. 1990. Ornithine lipid of Mycobacterium tuberculosis: its distribution in some slow and fast-growing mycobacteria. J. Gen. Microbiol. 136:773-778.

Lisa, T. A., Casale, C. H., and Domenech, C. E. 1994. Cholinesterase, and phospholipase $\mathrm{C}$ of Pseudomonas aeruginosa under hyperosmotic conditions in a high-phosphate medium. Curr. Microbiol. 28:71-76.

López-Lara, I. M., and Geiger, O. 2001. Novel pathway for phosphatidylcholine biosynthesis in bacteria associated with eukaryotes. J. Biotechnol. 91:211-221.

Merad, T., Archibald, A. R., Hancock, I. C., Harwood, C. R., and Hobot, J. A. 1989. Cell wall assembly in Bacillus subtilis: Visualization of old and new wall material by electron microscopic examination of samples stained selectively for teichoic acid and teichuronic acid. J. Gen. Microbiol. 135:645-655.

Miller, K. J., Shon, B. C., Gore, R. S., and Hunt, W. P. 1990. The phospholipid composition of Bradyrhizobium spp. Curr. Microbiol. 21:205210.

Minder, A. C., de Rudder, K. E. E., Narberhaus, F., Fischer, H.-M., Hennecke, H., and Geiger, O. 2001. Phosphatidylcholine levels in Bradyrhizobium japonicum membranes are critical for an efficient symbiosis with the soybean host plant. Mol. Microbiol. 39:1186-1198.

Minnikin, D. E., and Abdolrahimzadeh, H. 1974. The replacement of phosphatidylethanolamine and acidic phospholipids by an ornithineamide lipid and a minor phosphorous-free lipid in Pseudomonas fluorescens NCMB 129. FEBS (Fed. Eur. Biochem. Soc.) Lett. 43:257260.

Minnikin, D. E., Abdolrahimzadeh, H., and Baddiley, J. 1972. Variation of polar lipid composition of Bacillus subtilis Marburg with different growth conditions. FEBS (Fed. Eur. Biochem. Soc.) Lett. 27:16-18.

Minnikin, D. E., Abdolrahimzadeh, H., and Baddiley, J. 1974. Replacement of acidic phospholipids by acidic glycolipids in Pseudomonas diminuta. Nature (Lond.) 249:268-269.

Orgambide, G. G., Philip-Hollingsworth, S., Hollingsworth, R. I., and Dazzo, F. B. 1994. Flavone-enhanced accumulation and symbiosisrelated biological activity of a diglycosyl diacylglycerol membrane glycolipid from Rhizobium leguminosarum biovar trifolii. J. Bacteriol. 176:4338-4347.

Palaiomylitou, M. A., Kalimanis, A., Koukkou, A. I., Drainas, C., Anastassopoulos, E., Panopoulos, N. J., Ekateriniadou, L. V., and Kyriadis, D. A. 1998. Phospholipid analysis and fractional reconstitution of the ice nucleation protein activity purified from Escherichia coli overexpressing the inaZ gene of Pseudomonas aeruginosa. Cryobiology 37:67-76.

Perzl, M., Muller, P., Poralla, K., and Kannenberg, E. L. 1997. Squalenehopene cyclase from Bradyrhizobium japonicum: cloning, expression, sequence analysis and comparison to other triterpenoid cyclases. Microbiology 143:1235-1242.

Peschel, A., Jack, R. W., Otto, M., Collins, L. V., Staubitz, P., Nicholson, G., Kalbacher, H., Nieuwenhuizen, W. F., Jung, G., Tarkowski, A., van Kessel, K. P. M., and van Strijp, J. A. G. 2001. Staphylococcus aureus resistance to human defensins and evasion of neutrophil killing via the novel virulence factor $\mathrm{MprF}$ is based on modification of membrane lipids with L-lysine. J. Exp. Med. 193:1067-1076.

Phung, L. V., Chi, T. T. B., Hotta, H., Yabuchi, E., and Yano, I. 1995. Cellular lipid and fatty acid compositions of Burkholderia pseudomallei strains isolated from human and environment in Viet Nam. Microbiol. Immunol. 39:105-116.

Raetz, C. R. H., and Whitfield, C. 2002. Lipopolysaccharide endotoxins. Annu. Rev. Biochem. 71:635-700.

Ratledge, C., and Wilkinson, S. G. 1988. Microbial Lipids. Academic Press Limited, London.

Rock, C. O., Jackowski, S., and Cronan, J. E. 1996. Lipid metabolism in prokaryotes. Pages 35-74 in: Biochemistry of Lipids, Lipoproteins and Membranes. D. E. Vance and J. E. Vance, eds. Elsevier, Amsterdam, The Netherlands

Sakamoto, T., and Murata, N. 2002. Regulation of the desaturation of fatty acids and its role in tolerance to cold and salt stress. Curr. Opin. Microbiol. 5:206-210.

Sanda, S., Leustek, T., Theisen, M. J., Garavito, R. M., and Benning, C. 2001. Recombinant Arabidopsis SQD1 converts UDP-glucose and sulfite to the sulfolipid head group precursor UDP-sulfoquinovose in vitro. J. Biol. Chem. 276:3941-3946.

Savka, M. A., Dessaux, Y., Oger, P., and Rossbach, S. 2002. Engineering 
bacterial competitiveness and persistence in the phytosphere. Mol. Plant-Microbe Interact. 15:866-874.

Sheard, N. F., Tayek, J. A., Bistrian, B. R., Blackburn, G. L., and Zeisel, S. H. 1986. Plasma choline concentration in humans fed parenterally. Am. J. Clin. Nutr. 43:219-224.

Sherr, S. I., and Law, J. H. 1965. Phosphatidylcholine synthesis in Agrobacterium tumefaciens. II. Uptake and utilization of choline. J. Biol. Chem. 240:3760-3765.

Shukla, S. D., Green, C., and Turner, J. M. 1980. Phosphatidylethanolamine distribution and fluidity in outer and inner membranes of the gram-negative bacterium Erwinia carotovora. Biochem. J. 188:131135

Sohlenkamp, C., de Rudder, K. E. E., Röhrs, V., López-Lara, I. M., and Geiger, O. 2000. Cloning and characterization of the gene for phosphatidylcholine synthase. J. Biol. Chem. 275:18919-18925.

Sohlenkamp, C., López-Lara, I. M., and Geiger, O. 2003. Biosynthesis of phosphatidylcholine in bacteria. Prog. Lipid Res. 42:115-162.

Tahara, Y., Yamashita, T., Sogabe, A., and Ogawa, Y. 1994. Isolation and characterization of Zymomonas mobilis mutant defective in phosphatidylethanolamine $N$-methyltransferase. J. Gen. Appl. Microbiol. 40:389-396.

Tang, Y., and Hollingsworth, R. I. 1997. Digalactosyl diacylglycerols, plant glycolipids rarely found in bacteria, are major membrane components of bacteroid forms of Bradyrhizobium japonicum. Glycobiology 7:935-942.

Tang, Y., and Hollingsworth, R. I. 1998. Regulation of lipid synthesis in Bradyrhizobium japonicum: Low oxygen concentrations trigger phosphatidylinositol biosynthesis. Appl. Environ. Microbiol. 64:19631966.
Taylor, C. J., Anderson, A. J., and Wilkinson, S. G. 1998. Phenotypic variation of lipid composition in Burkholderia cepacia: a response to increased growth temperature is a greater content of 2-hydroxy acids in phosphatidylethanolamine and ornithine amide lipid. Microbiology 144:1737-1745.

Vinuesa, P., Neumann-Silkow, F., Pacios-Bras, C., Spaink, H. P. Martínez-Romero, E., and Werner, D. 2003. Genetic analysis of a pHregulated operon from Rhizobium tropici CIAT899 involved in acid tolerance and nodulation competitiveness. Mol. Plant-Microbe Interact. 16:159-168

Weissenmayer, B., Gao, J.-L., López-Lara, I. M., and Geiger, O. 2002. Identification of a gene required for the biosynthesis of ornithinederived lipids. Mol. Microbiol. 45:721-733.

Weissenmayer, B., Geiger, O., and Benning, C. 2000. Disruption of a gene essential for sulfoquinovosyldiacylglycerol biosynthesis in Sinorhizobium meliloti has no detectable effect on root nodule symbiosis. Mol. Plant-Microbe Interact. 13:666-672.

Wilderman, P. J., Vasil, A. I., Johnson, Z., and Vasil, M. L. 2001. Genetic and biochemical analyzes of a eukaryotic-like phospholipase D of Pseudomonas aeruginosa suggest horizontal acquisition and a role for persistence in a chronic pulmonary infection model. Mol. Microbiol. 39:291-303.

Wilderman, P. J., Vasil, A. I., Martin, W. E., Murphy, R. C., and Vasil, M. L. 2002. Pseudomonas aeruginosa synthesizes phosphatidylcholine by use of the phosphatidylcholine synthase pathway. J. Bacteriol. 184:4792-4799.

Yu, B., Xu, C., and Benning, C. 2002. Arabidopsis disrupted in SQD2 encoding sulfolipid synthase is impaired in phosphate-limited growth. Proc. Natl. Acad. Sci. U.S.A. 99:5732-5737. 
Erratum, Vol.16, No. 7, 2003

A review by López-Lara et al. (7:567-579) entitled "Membrane Lipids in Plant-Associated Bacteria: Their Biosyntheses and Possible Functions" contained errors in Table 2. The corrected table appears below.

Table 2. Bacteria containing open reading frames (ORFs) probably involved in phosphorous free membrane lipid biosynthesis ${ }^{\mathrm{a}}$

\begin{tabular}{|c|c|c|c|c|}
\hline \multirow[b]{2}{*}{ Organism $^{\text {b }}$} & \multicolumn{4}{|c|}{ Query (number of amino acids) } \\
\hline & $\begin{array}{c}\text { SqdB (406) } \\
\text { Sinorhizobium meliloti }\end{array}$ & $\begin{array}{l}\text { OlsA (292) } \\
\text { S. meliloti }\end{array}$ & $\begin{array}{c}\text { BtaA (416) } \\
\text { Rhodobacter sphaeroides }\end{array}$ & $\begin{array}{c}\text { SqhC (660) } \\
\text { Bradyrhizobium japonicum }\end{array}$ \\
\hline \multicolumn{5}{|l|}{$\begin{array}{l}\text { Proteobacteria } \\
\alpha \text {-Subdivision }\end{array}$} \\
\hline Agrobacterium tumefaciens ${ }^{\mathrm{c}}$ & $\ldots$ & $2 \times 10^{-88}$ & $10^{-107}$ & $\cdots$ \\
\hline Bradyrhizobium japonicum $^{\mathrm{c}}$ & $\ldots$ & $\ldots$ & $\ldots$ & $* 0.0$ \\
\hline Brucella melitensis $^{\mathrm{c}}$ & $\ldots$ & $8 \times 10^{-68}$ & $\cdots$ & $\ldots$ \\
\hline Mesorhizobium loti MAFF303099 & $\ldots$ & $5 \times 10^{-67}$ & $10^{-112}$ & $\ldots$ \\
\hline Rhizobium leguminosarum ${ }^{\mathrm{u}}$ & 0.0 & $7 \times 10^{-96}$ & $10^{-102}$ & $\ldots$ \\
\hline Rhizobium sp. NGR234pc & $\ldots$ & $\ldots$ & $\ldots$ & 0.0 \\
\hline Rhodobacter sphaeroides $s^{\mathrm{u}}$ & $* 0.0$ & $9 \times 10^{-18}$ & $* 0.0$ & $\ldots$ \\
\hline Rhodopseudomonas palustris ${ }^{\mathrm{u}}$ & $\ldots$ & $5 \times 10^{-57}$ & $2 \times 10^{-83}$ & 0.0 \\
\hline Sinorhizobium meliloti $^{\mathrm{c}}$ & $* 0.0$ & $* 10^{-166}$ & $10^{-107}$ & $\ldots$ \\
\hline \multicolumn{5}{|l|}{$\beta$-Subdivision } \\
\hline Burkholderia fungorum ${ }^{\mathrm{u}}$ & $\ldots$ & $4 \times 10^{-24}$ & $\ldots$ & 0.0 \\
\hline Ralstonia solanacearum ${ }^{\mathrm{c}}$ & $\cdots$ & $1 \times 10^{-19}$ & $\begin{array}{l}\cdots \\
\cdots\end{array}$ & $\ldots$ \\
\hline \multicolumn{5}{|l|}{$\gamma$-Subdivision } \\
\hline Escherichia coli & $\ldots$ & $\ldots$ & $\ldots$ & $\ldots$ \\
\hline Methylococcus capsulatus ${ }^{\mathrm{u}}$ & $\begin{array}{l}\cdots \\
\cdots\end{array}$ & $1 \times 10^{-23}$ & $\begin{array}{l}\cdots \\
\cdots\end{array}$ & $10^{-179}$ \\
\hline Pseudomonas aeruginosa $^{\mathrm{c}}$ & $\ldots$ & $2 \times 10^{-19}$ & $\ldots$ & $\ldots$ \\
\hline Pseudomonas fluorescens ${ }^{\mathrm{u}}$ & $\ldots$ & $3 \times 10^{-16}$ & $\ldots$ & $\ldots$ \\
\hline \multicolumn{5}{|l|}{ Cyanobacteria } \\
\hline Nostoc puntiforme $e^{\mathrm{u}}$ & $9 \times 10^{-85}$ & $\ldots$ & $\ldots$ & $10^{-118}$ \\
\hline Synechococcus sp. WH $8102^{u}$ & $10^{-142}$ & $\cdots$ & $\begin{array}{l}\cdots \\
\cdots\end{array}$ & $\ldots$ \\
\hline Prochlorococcus marinus $^{\mathrm{u}}$ & $10^{-145}$ & $\begin{array}{l}\cdots \\
\ldots\end{array}$ & $\begin{array}{l}\cdots \\
\cdots\end{array}$ & $\begin{array}{l}\cdots \\
\cdots\end{array}$ \\
\hline \multicolumn{5}{|l|}{ Firmicutes } \\
\hline Streptomyces coelicolor ${ }^{\mathrm{c}}$ & $\ldots$ & $3 \times 10^{-18}$ & $\ldots$ & $10^{-127}$ \\
\hline Bacillus subtilis $^{\mathrm{c}}$ & $\ldots$ & $\ldots$ & $\ldots$ & $8 \times 10^{-63}$ \\
\hline \multicolumn{5}{|l|}{ Archaea } \\
\hline Thermoplasma acidophilum ${ }^{\mathrm{c}}$ & $3 \times 10^{-60}$ & $\ldots$ & $\ldots$ & $\ldots$ \\
\hline Sulfolobus tokodaiic & $4 \times 10^{-62}$ & $\begin{array}{l}\cdots \\
\cdots\end{array}$ & $\begin{array}{l}\cdots \\
\cdots\end{array}$ & $\begin{array}{l}\cdots \\
\cdots\end{array}$ \\
\hline \multicolumn{5}{|l|}{ Eukaryotes } \\
\hline Arabidopsis thaliana ${ }^{\mathrm{n}}$ & $* 5 \times 10^{-81}$ & & $\ldots$ & $\ldots$ \\
\hline Candida albicans $^{\mathrm{u}}$ & $\ldots$ & $\ldots$ & $5 \times 10^{-17}$ & $\ldots$ \\
\hline Aspergillus fumigatus $^{\mathrm{u}}$ & $\ldots$ & $\cdots$ & $2 \times 10^{-8}$ & $\ldots$ \\
\hline
\end{tabular}

